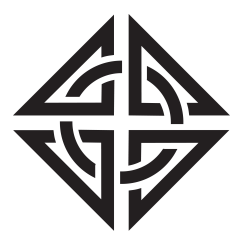

SCIENTIA
Sharif University of Technology

Scientia Iranica

Transactions E: Industrial Engineering

http://scientiairanica.sharif.edu

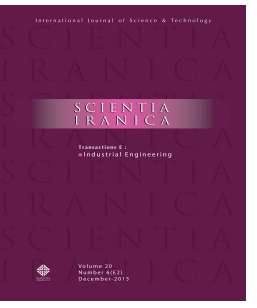

\title{
Dynamic pricing in a semi-centralized dual-channel supply chain with a reference price-dependent demand and production cost disruption: The case of Iran Khodro Company
}

\author{
F. Zarouri, S.H. Zegordi*, and A. Husseinzadeh Kashan \\ Faculty of Industrial and Systems Engineering, Tarbiat Modares University, P.O. Box 14115-143, Tehran, Iran. \\ Received 14 April 2019; received in revised form 2 September 2019; accepted 14 April 2020
}

\author{
KEYWORDS \\ Semi-centralized \\ dual-channel supply \\ chain; \\ Pricing; \\ Disruption; \\ Reference price; \\ Game theory; \\ Heuristic algorithm; \\ League championship \\ algorithm.
}

\begin{abstract}
During the years of imposed sanctions against Iran, Iran Khodro Company (IKCO) faced a hazardous situation due to the growing purchasing cost of Completely Knocked Down (CKD) parts and the emergence of new product variants in the competitive market. To analyze such situation, this study examines a multi-period semi-centralized dual-channel supply chain in which a common retailer (free market) and two manufacturers' (IKCO and Saipa as a major competitor) direct channels are confronted with reference price-dependent and stochastic demands. The problem is analyzed under Stackelberg and cooperative game scenarios using heuristic algorithm and a League Championship algorithm, respectively, as solution methods. Results obtained from solving the problem with IKCO data confirm the higher profitability of adopting the cooperative game and its remarkable resilience for all products' memory types, i.e., short/long term memory against production cost disruption which is imposed against IKCO in some periods. Besides calculating Saipa's optimal wholesale price in disruption periods, our approach with a support of experimental analyses is able to assign a supply chain's degree of resilience against disruptions to its product's memory type and power structure.
\end{abstract}

(C) 2021 Sharif University of Technology. All rights reserved.

\section{Introduction}

In today's industrial world, a considerable increase in the number of manufacturers stimulates their concern about survivability and as a result, persuades them to enhance their products to meet customers' preferences

*. Corresponding author. Tel/Fax: +982182883394 E-mail addresses: Farnia.Zarouri@modares.ac.ir (F. Zarouri); Zegordi@modares.ac.ir (S.H. Zegordi); a.kashan@modares.ac.ir (A. Husseinzadeh Kashan)

doi: $10.24200 /$ sci.2020.53309.3188 and interests. Therefore, manufacturers should ensure a close relationship with customers. Dual-channel supply chain is a type of supply chain that provides this relationship. The dual-channel supply chain, as evident by its name, has two selling channels including (a) retail channel (also known as traditional channel) in which a product is offered by retailer and (b) E-direct channel wherein selling of a product is conducted through both the manufacturer and the internet. Academic researches' tendency to the issue of the dual-channel supply chain and the application of this chain by the top manufacturers like Samsung, HP, IBM, Sony, Dell, Lenovo, Panasonic, and Pioneer Electrics demonstrate 
its profitability and its vital role in the survival of a manufacturer [1]. Some Iranian companies including IKCO, Saipa, Pars Shahab Light Company, and Rasa Nour Neishabour Company have two selling channels.

Pricing is a crucial decision in the supply chain that affects its profitability. The supply chain pricing enjoys a rich literature. Given that most of the researches have utilized the game-theory approach, some of them are given briefly in this section. Sana et al. (2014) studied a three-layer supply chain and considered both collaborative and Stackelberg scenarios [2]. Modak et al. (2016) studied a closedloop supply chain and considered cooperative and Stackelberg game scenarios; in the Stackelberg game, retailers' competition was modeled under Cournot and collusion games [3]. Modak et al. (2016) investigated a supply chain wherein a manufacturer-led Stackelberg vertical game was considered in which the retailers exhibited three different behaviors, namely Cournot, Collusion, and Stackelberg. They utilized all units of discount contract with franchise fee as a channel conflict respondent [4]. Sana et al. (2017) considered a knowledge management approach in the agroindustrial supply chain of cocoa wherein they took into consideration the collection center-led Stackelberg and collaboration scenarios [5]. Modak et al. (2018) considered a two-echelon closed-loop supply chain in which besides considering three possible collection activities of used products for recycling, namely retailer led collection, manufacturer led collection, and third party led collection, they introduced the concept of subgame perfect equilibrium and an alternative bargaining strategy to resolve the channel conflict and distribute surplus profits [6]. Roy et al. (2018) studied a twoechelon supply chain and obtained optimal order quantity under Estackelberg, Bertland, Cournot-Bertland, and integrated scenarios [7].

It is worth mentioning that the significance of pricing to the dual-channel supply chain is higher than that to the one-channel supply chain due to price competition that generates channel conflicts. Multiplicity of the channel conflict-related researches in the literature proves the critical importance of this field. These researches have analyzed the channel conflict and introduced some strategies to reduce the effects of the conflict, additionally. The strategies are divided into two groups including use of contracts and improvement of sales services as well as customer loyalty. In the first group, Tsay and Agrawal (2004) utilized game theory to examine the channel conflict and coordinate the chain members as well [8]. Mukhopadyay et al. (2006) instituted profit sharing contract while the retailer had the ability to add some values to the product cost [9]. Yan (2008) used the game theoretic approach to analyze the strategic role of profit sharing among the chain members and improve coordination and performance of the chain [10]. Later, Chen (2015) and Panda et al. (2015) utilized the profit-sharing contract in their researches [11,12]. Cai et al. (2009) investigated the influence of quantity discount contract on competition taking place in the dual-channel supply chain [13]. Cai (2010) studied the effects of channel coordination contract on the members in two onechannel and two dual-channel supply chains scenarios [14]. Yan and Pei (2011) considered a multiple-channel supply chain consisting of numerous manufacturers, each having private information about customers' demand, and one retailer. They represented information sharing contract [15]. Cao (2013) presented optimum wholesale price contract in a dual-channel supply chain under cost information asymmetry and total information asymmetry scenarios [16]. Modak et al. (2014) studied a dual-channel supply chain and took into consideration social responsibility in both decentralized and centralized scenarios. As a channel coordination strategy, they introduced all-unit quantity discounts with an agreement on a franchise fee and surplus profit division using bargaining [17].

Matsui (2016) suggested determining the direct channel's price before wholesale price, or simultaneously, to prevent channel conflict effects [18]. Li et al. (2016) studied a green dual-channel supply chain and proposed a two-part tariff contract to coordinate the decentralized supply chain [19]. Li et al. (2016) considered a supply chain with a risk-neutral manufacturer and a risk-averse retailer and introduced a risk-sharing contract for the coordination of the chain members [20]. Liu et al. (2016) investigated the effects of risk aversion on the optimal strategies of a dualchannel supply chain under complete symmetric and asymmetric information scenarios. They concluded that the information asymmetry increased the wholesale and retail prices while reducing the direct sale price [21]. Wang et al. (2017) considered the pricing and service decisions of complementary products in a dual-channel supply chain with two manufacturers and one retailer such that one of the manufacturers uses direct channel besides the retailer [22]. Xu et al. (2018) considered the coordination problem in a dual-channel supply chain under mandatory carbon emission capacity regulation. In this regard, costumers are either brand loyal or retailer loyal; they investigated the problem in centralized and decentralized scenarios. They also introduced online channel price discount and offline channel price discount contracts for the coordination. Two different types of pricing form and different structures were analyzed using backward induction [23]. Modak and Kelle (2019) addressed the problem of coordinating a dual-channel supply chain with one manufacturer and one retailer, all having a price and delivery time dependent stochastic demand. They proposed a hybrid all-unit quantity discount 
along with a franchise fee contract for the coordination of both centralized and decentralized scenarios [24].

The second group is dedicated to the improvement of sales services and customer loyalty. Customers' preferences for channel choice affect the sales level significantly. As the manufacturer sells its product through the direct channel, the retailer tries to obtain customer satisfaction and increase the sales scale by means of improving the sales services. Dan et al. (2011) studied optimal decisions for the pricing and sales services of the retailer in both centralized and decentralized dual-channel supply chain scenarios [25]. Zhao et al. (2017) considered the pricing problem in a dual-channel supply chain with two manufacturers and one retailer along with complementary products. They presented four pricing game models and evaluated them based on customer loyalty and level of complementarity [26].

Another factor affecting the profitability of a supply chain is unpredicted disruption. Disruption management is one of the most important aspects of supply chain management since it affects the chain performance directly. The researches carried out in recent years have categorized the disruptions into four groups. The intended groups include demand disruption [27-31], supply disruption [32-34], production cost disruption [35], simultaneous demand and production cost disruptions [36-39].

There are only three research studies in the literature of the dual-channel supply chain that are related to risk and disruption. Huang et al. (2012, 2013) studied demand and production cost disruptions in centralized and decentralized dual-channel supply chains, respectively [40,41]. Xu et al. (2014) proposed a pricing model in risk-averse centralized and decentralized dual-channel supply chains [42].

Reference price, abundantly used in the economics and marketing literature, does not enjoy a rich literature in the supply chain field. The reference price is the expected buying price of a product formed by customers, and based on the literature, it reflects the customers' last purchasing experiences [43]. Customers conceive an expected price to buy a commodity. This expected price is known as the reference price. There are two possible situations in the market: if the reference price is lower than observed price (actual price of the commodity), then the demand increases; otherwise, the demand decreases. There are several ways to determine the reference prices including selling price of the best brand and buying price of the last bought brand [44]. The notion of the reference price is originated from Adaptation-level theory and Assimilation [45]. There are only four research studies in the supply chain literature that have utilized the reference price. Geng et al. (2010) presented a pricing strategy in a supply chain with the reference price and deterministic demand [46]. Zhang et al. (2013) studied the influence of advertisement on the reference price quantity in a supply chain [43]. Zhang et al. (2014) considered a supply chain wherein there are the reference price effects and members determine their pricing strategy independently [47]. Lin (2016) analyzed price promotion in a supply chain and concluded that the reference price mitigated double-marginalization effects and improved the chain efficiency [48]. Taleizadeh et al. (2017) studied a three-level closed-loop supply chain and proposed a joint optimization model of pricing strategies, quality levels, effort decisions, and return policy regarding the reference price under different game structure scenarios [49].

The reviewed literature in this study reveals some weaknesses as follows:

- The majority of the researches targeting the dualchannel supply chain pricing have been taken into consideration from the managerial point of view. However, few research studies have taken this problem into account from the operational perspective;

- Disruption in the dual-channel supply chain has a limited extent of literature;

- The researches frequently use a supply chain with one manufacturer and one retailer, some of whom have a supply chain with one manufacturer and multiple retailers. There are some researches that consider supply chains composed of multiple manufacturers. However, in the real world, there are a considerable number of supply chains that have more than one manufacturer.

Furthermore, the sanctions imposed against Iran's industry have resulted in substantial loss and economic stagnation. The automobile industry, one of the biggest industries of Iran, has faced many challenging problems in supplying raw material requirements under sanctions. Peugeot 206 is among IKCO'S automobiles that have faced critical issues as IKCO was denied access to the products of Peugeot Company; thus, its CKD parts supply was disrupted. First strategy for IKCO to challenge this disruption was meeting its requirements via intermediate countries. Thereby, purchasing cost of CKD parts had a considerable increment. On the other hand, Saipa Company proceeded to purchase production lines of Chinese automobiles and launched producing these automobiles and entering them into Iran automobile market. The act of Saipa which is regarded as a threat to IKCO has stimulated its concern since the Chinese automobiles are absorbing demand due to lower prices; hence, they are regarded as competitors of IKCO'S automobiles. For these reasons, this research addresses the dual-channel supply chain disruption and pricing area. This paper considers a dual-channel supply chain that consists of two competing manufacturers (IKCO and Saipa), each 
owning two selling channels and a common retailer. One manufacturer (IKCO) suffered disruption in the production cost (excluding the purchasing cost of CKD parts) that would occur in some periods.

\section{Problem definition}

This study considers a dual-channel supply chain with two competing manufacturers and a common retailer. Each manufacturer produces different, yet substitutable, products and sells them through the direct channel and the retailer is known as the retail channel. There is a price competition among these four channels. The issue has multiple periods and, in some periods, one manufacturer faces disruption in the production cost, which is due to the purchasing cost of the raw materials. The popularity of the corresponding manufacturer is lowered inconsiderably because of its high-status brand. Demand $\left(D_{i j t}\right)$ facing all selling channels is stochastic and it depends on the reference price and other channels' selling price. In each period, the retailer places order for the quantity $q_{\text {irt }}$ from manufacturer $i$ considering its expected demand $\left(d_{i r t}\right)$ and positive inventory of the last previous period $\left(I_{i r t-1}^{+}\right)$. Manufacturer $i$ produces the product at unit cost $C_{i t}$ which has a different value in disruption periods and provides the retailer's order completely at the unit wholesale price $w_{i t}>C_{i t}$ and allocates the quantity $q_{i d t}$ to its direct channel regarding the expected demand $\left(d_{i d t}\right)$. Considering the quantity of products $i$ in channel $r$ as $q_{i r t}^{\prime}$ (sum of $q_{i r t}$ and $I_{i r t-1}^{+}$), if the retailer's demand (manufacturer $i^{\prime}$ s demand) is less than $q_{i r t}^{\prime}\left(q_{i d t}\right)$, the retailer (manufacturer $i$ ) endures holding cost of $h_{r}\left(h_{i}\right)$ per inventory unit. Conversely, if $q_{i r t}^{\prime}<D_{i r t}\left(q_{i d t}<D_{i d t}\right)$, then the retailer (manufacturer $i$ ) bears lost sales cost of $b_{r}$ $\left(b_{i}\right)$ per unit. Production level $\left(Q_{i t}\right)$ of manufacturer $i$ in a period is calculated by adding $q_{i r t}$ to $q_{i d t}$ and subtracting $I_{i t-1}^{+}$(positive inventory of the last previous period in case of $\left.q_{i d(t-1)}>D_{i d(t-1)}\right)$ from it. Broadly, decision variables for manufacturer $i$ are $p_{i d t}$, $w_{i t}, q_{i d t}$, and $Q_{i t}$ and for the retailer are $q_{i r t}$ and $p_{i r t}$.

This research study addresses the challenges associated with IKCO. IKCO is the manufacturer that has been facing disruption in the production cost, and its counterpart is Saipa. These two carmaker companies are the major players in Iran and most probably in the Middle East. The retailer is assumed to be performing in the free market that sells the product of the mentioned manufacturers. The product of manufacturers is selected in such a way that they have about equal prices. Therefore, Peugeot 206 for IKCO and Brilliance (H230) for Saipa are selected. The aim of this paper is to develop an appropriate pricing model such that it can represent the optimum level

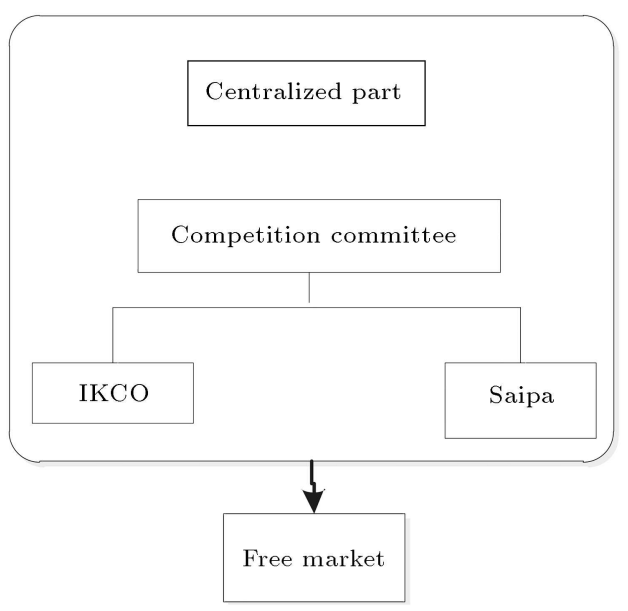

Figure 1. Semi-centralized dual-channel supply chain structure of the case study.

of prices for each period in order to maximize each member's profit.

As shown in Figure 1, IKCO and Saipa are in control of Competition Committee, i.e., a State Organization that investigates prices to control inflation and create a stable and sustainable economic growth, hence innovating semi-centralized dual-channel supply chain. This type of supply chain is a compound of centralized and decentralized supply chains, that is to say, some parts of the chain act centrally, but these parts have a decentralized relationship with the others.

\section{Mathematical modeling}

As mentioned in Section 2, the proposed problem is a multi-period one and the extra inventory in a period is transferred to the next period. For this reason and due to the effect of the reference price on the demand in periods, the dynamic mathematical model is used to model the problem. This section represents each member's mathematical model of the chain considering the definition of relevant parameters in the following:

\section{Indexes}

$j, k, \quad$ Channel indexes $j, k=r, d$

$i, l, \quad$ Manufacturer (product) indexes

$i, l=1,2$

\section{Parameters}

$R \quad$ Retail channel index

$D \quad$ Direct channel index

$D_{i j t} \quad$ Total demand for product $i$ in channel $j$ in period $t$

$d_{i j t} \quad$ Expected demand for product $i$ in channel $j$ in period $t$

$\beta_{i j t} \quad$ Elasticity coefficient for product $i$ in channel $j$ in period $t$

$y_{l k t} \quad$ Cross effect coefficient of $p_{l k t}$ 
$\theta_{i j} \quad$ Market share of the $j$ th channel of product $i$

$P_{i t} \quad$ Average observed price of the $i$ th product in period $t$

$P_{i j t} \quad$ Price of product $i$ in channel $j$ in period $t$

$\mu_{i j} \quad$ Potential demand of the $i$ th product in channel $j$ if $p_{i j t}=0$

$M \quad$ Market potential demand if $\forall i, j$ $p_{i j t}=0$

A Memory effect

$g_{1} \quad$ Customers' sensitivity coefficient for the difference between reference and observed prices in non-disruption periods

Customers' sensitivity coefficient for the difference between reference and observed prices in disruption periods

$\varepsilon_{i j t} \quad$ Stochastic element of demand function for product $i$ in channel $j$ in period $t$

$M_{i t} \quad$ Price of product $i$ determined by the marketing department of manufacturer $i$

$Q_{i t} \quad$ Production quantity of manufacturer $i$ in period $t$

$q_{\text {irt }} \quad$ Order level of the $i$ th product of the retailer in period $t$

$q_{\text {irt }}^{\prime} \quad$ The quantity of the $i$ th products from the retailer in period $t$

$q_{\text {idt }} \quad$ Level of products allocated to channel $d$ of manufacturer $i$ in period $t$

$I_{i t} \quad$ Inventory level of manufacturer $i$ in period $t$

$I_{i t}^{+} \quad$ Positive inventory level of manufacturer $i$ in period $t$

$I_{\text {irt }} \quad$ Inventory level of the $r$ th channel of product $i$ in period $t$

$I_{i r t}^{+} \quad$ Positive inventory level of the $r$ th channel of product $i$ in period $t$

$c_{i t}$

$\Delta c_{i t}$

Unit production cost of product $i$ in period $t$

Unit production cost variation of product $i$ in period $t$

$C_{i t} \quad$ Total unit production cost of product $i$ in period $t$

$H_{r} \quad$ Unit holding cost of the retailer

$h_{i} \quad$ Unit holding cost of manufacturer $i$

$b_{r} \quad$ Unit lost sales cost of the retailer

$b_{i} \quad$ Unit lost sales cost of manufacturer $i$

$\begin{array}{ll}\Pi_{i r t} & \begin{array}{l}\text { Profit function of the } r \text { th channel of } \\ \text { product } i \text { in period } t\end{array} \\ \Pi_{r t} & \text { Profit function of the retailer in period } \\ \Pi_{i t} & \begin{array}{l}t \\ \text { Profit function of manufacturer } i \text { in } \\ \text { period } t\end{array} \\ \Pi_{c p t} & \begin{array}{l}\text { Profit function of the centralized part } \\ \text { in period } t\end{array} \\ \Pi_{s c} & \begin{array}{l}\text { Total profit function of the dual- } \\ \text { channel supply chain }\end{array}\end{array}$

Binary parameters

$$
\varphi= \begin{cases}1 & \text { If it is a no disruption period } \\ 0 & \text { O.W. }\end{cases}
$$

\subsection{Demand function}

IKCO historical data illustrate that the difference in the number of real and estimated demands is somewhat low. Moreover, they have demonstrated that the demand in a period depends on its previous periods' demands. Therefore, the demand facing all selling channels is the reference price and other channels' selling price is dependent and stochastic. Now, the demand function for each selling channel in every period is denoted by:

$$
D_{i j t}=d_{i j t}+\varepsilon_{i j t} \text {. }
$$

Eq. (1) indicates that the demand function comprises two parts: Deterministic and stochastic demands. The expected deterministic demand function is defined as follows:

$$
\begin{aligned}
d_{i j t}= & \mu_{i j}-\beta_{i j t} p_{i j t}+\sum_{\forall k \in(d, r)} \sum_{\substack{l=1 \\
l k \neq i j}}^{2} y_{l k t} p_{l k t} \\
& +\left(\varphi g_{1}+(1-\varphi) g_{2}\right)\left(r_{i t}-p_{i t}\right),
\end{aligned}
$$

where $\mu_{i j}=\mu \times \theta_{i j}$ and:

$$
\sum_{i=1}^{2} \sum_{j \in\{r, d\}} \theta_{i j}=1 \text {. }
$$

$\beta_{i j t}$ is the elasticity coefficient of the $i$ th product in the $j$ th channel in period $t$. This coefficient indicates the reverse effects of price changes in a channel on its demand. $y_{i j t}$ is the cross-effect coefficient of the $i$ th product in channel $k$ in period $t$. This coefficient measures the direct impact of a channel's price changes on the other channels' demands. $g_{1}$ and $g_{2}$ are customers' sensitivity coefficients for the difference between the reference and observed prices, respectively, in no disruption and disruption periods. If the reference and observed prices have a considerable difference, $g$ has a greater value. $\varphi$ is the binary disruption parameter and gets 1 and 0 in no disruption and disruption periods, respectively. $r_{i t}$ is called the reference price that is calculated as follows: 


$$
r_{i t}=\alpha r_{i(t-1)}+(1-\alpha) p_{i(t-1)} \quad 0 \leq \alpha \leq 1,
$$

where $\alpha$, which is the crucial parameter in determining the reference price, is called memory effect. The memory effect is customers' memory about previous prices. If the product has a short-time memory, the value of $\alpha$ is close to zero; else, if the product has a long-time memory, the quantity of $\alpha$ is given close to 1 . $p_{i(t-1)}$ is the average observed price in the last previous period and is determined as follows:

$$
p_{i(t-1)}=\frac{\left(p_{i r(t-1)}+p_{i d(t-1)}\right)}{2} .
$$

The other conditions are assumed as follows [50]:

$$
\begin{aligned}
& \frac{\partial d_{i j t}}{\partial p_{i j t}}<0 \quad i=\{1,2\}, \quad j=\{r, d\}, \\
& \frac{\partial d_{i j t}}{\partial p_{l k t}}>0 \quad i, l=\{1,2\}, \quad j, k=\{r, d\}, \quad i j \neq l k, \\
& \mathrm{~B}_{i j t}>y_{l k t} \quad i, l=\{1,2\}, \quad j, k=\{r, d\} .
\end{aligned}
$$

As demonstrated in Eq. (5), $d_{i j t}$ decreases with increase in $p_{i j t}$. This amount of decrease is transferred to the other manufacturer's channels or another channel of the corresponding manufacturer. Eq. (6) demonstrates increase in $d_{i j t}$ when $p_{l k t}$ decreases. Eq. (7) indicates the higher value of $\beta_{i j t}$ than $y_{l k t}$.

\subsection{Profit functions}

In consideration of total revenue and total cost for the retailer and defining $q_{i r t}^{\prime}=q_{i r t}+I_{i r t-1}^{+}$as the number of products $i$, the expected profit function of the retail channel $i$ can be given as follows:

$$
\begin{aligned}
& \Pi_{i r t}= \\
& \left\{\begin{array}{l}
p_{i r t} D_{i r t}-w_{i t} q_{i r t}-h_{r}\left(q_{i r t}^{\prime}-D_{i r t}\right) ; D_{i r t}<q_{i r t}^{\prime} \\
p_{i r t} q_{i r t}^{\prime}-w_{i t} q_{i r t}-b_{r}\left(D_{i r t}-q_{i r t}^{\prime}\right) ; D_{i r t}>q_{i r t}^{\prime}
\end{array}\right.
\end{aligned}
$$

By defining $z_{i r t}=q_{i r t}^{\prime}-d_{i r t}$ as the stocking factor, the relevant expected profit function can be represented as follows:

$$
\begin{aligned}
& \Pi_{i r t}= \\
& \left\{\begin{array}{c}
p_{i r t}\left(d_{i r t}+\varepsilon_{i r t}\right)-w_{i t}\left(d_{i r t}+z_{i r t}\right) \\
\quad-h_{r}\left(z_{i r t}-\varepsilon_{i r t}\right)+w_{i t} I_{i r t-1}^{+} ; \varepsilon_{i r t}<z_{i r t} \\
p_{i r t}\left(d_{i r t}+z_{i r t}\right)-w_{i t}\left(d_{i r t}+z_{i r t}\right) \\
\quad-b_{r}\left(\varepsilon_{i r t}-z_{i r t}\right)+w_{i t} I_{i r t-1}^{+} ; \varepsilon_{i r t}>z_{i r t}
\end{array}\right.
\end{aligned}
$$

The expected profit function can be written as follows:

$$
E\left(\Pi_{r t}\right)=\sum_{i=1}^{2} \int_{-\infty}^{z_{i r t}} p_{i r t}\left(d_{i r t}+x\right)-h_{r}\left(z_{i r t}-x\right) f(x) d x
$$

$$
\begin{aligned}
& +p_{i r t}\left(d_{i r t}+z_{i r t}\right)-\int_{z_{i r t}}^{\infty} b_{r}\left(x-z_{i r t}\right) f(x) d x \\
& -w_{i t}\left(d_{i r t}+z_{i r t}-I_{i r t-1}^{+}\right) .
\end{aligned}
$$

As demonstrated in Eqs. (11) and (12), the expected profit function can be reduced to (proof is represented in Appendix A):

$$
\begin{aligned}
\Theta\left(z_{i r t}\right)= & \int_{z_{i r t}}^{+\infty}\left(x-z_{i r t}\right) f(x) d x \\
\Phi\left(z_{i r t}\right)= & \int_{-\infty}^{z_{i r t}}\left(z_{i r t}-x\right) f(x) d x \\
E\left(\Pi_{r t}\right)= & \sum_{i=1}^{2}\left\{\left(p_{i r t}-w_{i t}\right) d_{i r t}-\left\{\left(w_{i t}+h_{r}\right) \Phi\left(z_{i r t}\right)\right.\right. \\
& \left.+\left(p_{i r t}+b_{r}-w_{i t}\right) \Theta\left(z_{i r t}\right)\right\} \\
& \left.+\left(p_{i r t}+w_{i t}\right) E\left(\varepsilon_{i r t}\right)+I_{i r t-1}^{+} w_{i t}\right\}
\end{aligned}
$$

The retailer's constraints are:

$$
\begin{aligned}
& q_{i r t}=z_{i r t}+d_{i r t}-I_{i r t-1}^{+}, \\
& I_{i r t}=I^{+}{ }_{i r t}+q_{i r t}-\left(d_{i r t}+\varepsilon_{i r t}\right) \quad I_{0}-\text { Fixed, } \\
& I_{i r t-1}^{+}=\max \left(I_{i r t-1}, 0,\right) \\
& p_{i r t} \leq M_{i t} .
\end{aligned}
$$

Constraints (14) and (15) calculate the order quantity of product $i$ and the inventory amount, respectively, in period $t$ in which $I_{i r t-1}^{+}$is the positive inventory of the last previous period that Eq. (16) calculates it. Eq. (17) is associated with constraining $p_{i r t}$ such that it should be less than $M_{i t}$ as applied by the marketing department.

Expected profit function of the manufacturer $i$ can be written as follows:

$$
\begin{aligned}
& \Pi_{i t}= \\
& \left\{\begin{array}{c}
w_{i t} q_{i r t}+p_{i d t} D_{i d t}-C_{i t} Q_{i t}-h_{i}\left(q_{i d t}-D_{i d t}\right) \\
D_{i d t}<q_{i d t} \\
w_{i t} q_{i r t}+p_{i d t} q_{i d t}-C_{i t} Q_{i t}-b_{i}\left(D_{i d t}-q_{i d t}\right) ; \\
D_{i d t}>q_{i d t}
\end{array}\right.
\end{aligned}
$$

where $C_{i t}$ has a different value in each period despite disruption or non-disruption and is calculated as follows:

$$
C_{i t}=c_{i t}+(1-\varphi) \Delta c_{i t},
$$

where $c_{i t}$ is the production cost in no disruption period 
and is regarded as the basic production cost. $\varphi$ is the binary disruption parameter.

Manufacturer $i^{\prime}$ s expected profit function can be represented as Eq. (20) using $z_{i d t}=q_{i d t}-d_{i d t}$ and Eqs. (11) and (12):

$$
\begin{aligned}
E\left(\Pi_{i t}\right)= & w_{i t} q_{i r t}+p_{i d t} d_{i d t}-C_{i t} Q_{i t}-\left\{h_{i} \Phi\left(z_{i d t}\right)\right. \\
& \left.+\left(p_{i d t}+b_{i}\right) \Theta\left(z_{i d t}\right)\right\}+2 E\left(\varepsilon_{i d t}\right)
\end{aligned}
$$

The inventory quantity and the production amount in period $t$ are calculated as follows:

$$
\begin{aligned}
& I_{i t}=q_{i d t}-D_{i d t}, \\
& Q_{i t}=q_{i d t}+q_{i r t}-I_{i t-1}^{+} .
\end{aligned}
$$

Now, the expected profit of the centralized part is given as follows:

$$
\Pi_{c p t}=\sum_{t=1}^{T} \sum_{i=1}^{2} E\left(\Pi_{i t}\right) .
$$

Total expected profit of the dual-channel supply chain is written as follows:

$$
E\left(\Pi_{s c}\right)=\sum_{t=1}^{T}\left\{E\left(\Pi_{c p t}\right)+E\left(\Pi_{r t}\right)\right\}
$$

\section{Stackelberg game}

According to Figure 1, the semi-centralized supply chain consists of two parts. First, Competition Committee determines the optimal wholesale prices; afterwards, the retailer proceeds to set the optimal price level for the retail channels; hence, the problem has two stages and the Stackelberg game should be used in this problem wherein the centralized part is the leader and the retailer is the follower. In the second stage of the Stackelberg game, the Nash equilibrium is used due to the price competition among the channels. The Nash equilibrium represents an optimum level for all channels' price and quantity. Subsequently, responses obtained for the Nash equilibrium variables are replaced in $\Pi_{c p t}$, and the two-stage mathematical model is converted into a one-stage mathematical model resultantly. In this stage, concavity of $\Pi_{c p t}$ is analyzed and the optimum response for each $w_{i t}$ is obtained in the case of concavity.

In the Nash equilibrium, concavity of $\Pi_{r t}$ for $p_{i r t}$ is analyzed to find the best responses for the retailer. Proposition 1 gives the obtained results.

Proposition 1: $\Pi_{r t}$ with respect to $p_{i r t}$ is negative definite. It indicates that $\Pi_{r t}$ is strictly concave. Accordingly, the optimum response for $p_{\text {irt }}$ is:

$$
\begin{aligned}
\frac{\partial \Pi_{r t}}{\partial p_{i r t}}= & 0 \\
& \Rightarrow p_{i r t}=w_{i t} \\
& \frac{\Theta\left(z_{i r t}\right)-d_{i r t}-\left(p_{(3-i) r t}-w_{(3-i) t}\right) \frac{\partial d_{(3-i) r t}}{\partial p_{i r t}}}{\frac{\partial d_{i r t}}{\partial p_{i r t}}} .
\end{aligned}
$$

In Eq. (25), the denominator has a negative value $\left(\partial d_{i r t} / \partial p_{\text {irt }}=-\left(\beta_{i j t}+g\right)\right)$. In the numerator, all parameters and variables have negative sign other than $\Theta\left(z_{i r t}\right)$. The sum of these negative values divided by negative sign of the denominator is converted to a positive value. As a result, only $\Theta\left(z_{i r t}\right)$ has a negative effect on $p_{\text {irt }}$. Taking into consideration the stoking factor equation and Eq. (11), it is evident that $\Theta\left(z_{i r t}\right)$ has a positive relation with the inventory and has a negative impact on the profit. The following notes can be induced:

- The inventory has a negative effect on $p_{\text {irt }}$ level;

- It is obvious that Eq. (25) has a positive value and, hence, $p_{\text {irt }}>0$ and $p_{\text {irt }}>w_{i t}$.

Apparently, $p_{\text {irt }}$ and $p_{(3-i) r t}$ are price variables in the retail channels that can be simply obtained using Eq. (25). Now, in Eq. (25), there is $p_{(3-i) r t}$ in it. In order to have an applicable equation to yield the optimal price for each retail channel particularly in Subsection 4.1, $p_{(3-i) r t}$ should be omitted from Eq. (25) somehow. According to Zhang et al. (2012), the existing approach in the literature is to replace $p_{(3-i) r t}$ with its equation (Eq. (25) corresponding to $p_{(3-i) r t}$ ). It is feasible to do so if Hessian Matrix of $\Pi_{r t}$ with respect to $p_{i r t}$ and $p_{(3-i) r t}$ is strictly concave [51]. Proposition (2) gives the results.

Proposition 2: The Hessian Matrix of $\Pi_{r t}$ with respect to $p_{\text {irt }}$ and $p_{(3-i) r t}$ is negative definite (proof is represented in Appendix B). As a result, $\Pi_{r t}$ is strictly concave with respect to $p_{\text {irt }}$ and $p_{(3-i) r t}$; hence, it is allowable to place $p_{(3-i) r t}$ in Eq. (25). The simplified equation for $p_{\text {irt }}$ is as follows:

$$
\begin{aligned}
p_{i r t}= & \frac{\left(\frac{x \Theta\left(z_{i r t}\right)-f \Theta\left(z_{(3-i) r t}\right)}{x y}\right)-\left(\frac{x d_{i r t}-d_{(3-i) r t}}{x y}\right)}{1-\frac{g}{x y}} \\
& +\frac{w_{i t}\left(1-\frac{g}{x y}\right)-w_{(3-i) t}\left(\frac{1-f}{y}\right)}{1-\frac{g}{x y}}
\end{aligned}
$$

where:

$$
\begin{aligned}
& x=\frac{\partial d_{(3-i) r t}}{\partial p_{(3-i) r t}}, \quad y=\frac{\partial d_{i r t}}{\partial p_{i r t}}, \quad g=\frac{\partial d_{i r t}}{\partial p_{(3-i) r t}} \\
& f=\frac{\partial d_{(3-i) r t}}{\partial p_{i r t}}
\end{aligned}
$$

In this section, the heuristic algorithm used as a solution method for this problem is explained. The 
reason for selecting the heuristic method is that in the first stage of the Stackelberg game, $\Pi_{c p t}$ is not concave in $w_{i t}$. Therefore, the existing heuristic algorithm in the literature is utilized.

To determine the value of $z_{i r t}$, Proposition 3 represented in the literature [52] is used.

Proposition 3: If $z$ is defined in a range $[-A, A]$, the optimal level for $z$ is the highest value obtained from solving $\partial\left(\Pi_{z}\right) / \partial z=0$. Otherwise, the optimal level for $z$ is $(-A)$. According to the literature, the proper range of service levels is $[0.85,0.95]$. It is worth mentioning that this study solves the equation $\partial\left(\Pi_{z}\right) / \partial z=0$ to set the optimal quantity for $z_{i r t}$. The obtained results demonstrate that no solution for $z_{i r t}$ has been found. Therefore, Referring to Proposition 3, the optimal level for $z_{i r t}$ is $F^{-1}(0.85)$. The level for $z_{i j t}$ is equal in all periods, as in Proposition 3.

In this section, the existing heuristic algorithm in the literature [52] is represented in the following.

\subsection{Heuristic algorithm}

The steps of the heuristic algorithm are explained in the following:

Step 1: For $i=1,2$ and $t=1, \cdots, T$, set a value to $w_{i t}$ randomly with respect to $C_{i t}$ and set $L=0$;

Step 2: Determine the number of other variables at random using $w_{i t}$ for $i=1,2$ and $t=1, \cdots, T$ and calculate $\Pi_{r t}$ and $\Pi_{c p t}$. Subsequently, select a random number for $i$ from set $i=\{1,2\}$;

Step 3: For $t=1, \cdots, T$, choose a random value for $w_{i t}$ from a small group whose lower bound is greater than $c_{i t}$. Generate $p_{i d t}$ randomly in a small range whose lower bound is greater than $w_{i t}$;

Step 4: For $i=1,2$ and $t=1, \cdots, T$, obtain the value of $p_{\text {irt }}$ using Eq. (26) and solve the problem. If the difference between $\Pi_{r t}$ and its previous calculated value is less than $\Delta$, the quantities of $p_{i r t}, p_{i d t}, w_{i t}$, and $\Pi_{r t}(i=1,2$ and $t=1, \cdots, T)$ are the Nash equilibrium quantities and then, go to Step 6; else, go to Step 5;

Step 5: For $i=1,2$ and $t=1, \ldots, T$, add up $\varepsilon$ to each bound of the initial range of $p_{i d t}$ and generate $p_{i d t}$ regarding the new range and go back to Step 4 .

Step 6: Calculate $\Pi_{c p t}$ using the equilibrium quantities. If the value of $\Pi_{c p t}$ is less than its previous calculated value, the obtained equilibrium value is the Stackelberg point and, hence, is the best achieved response to the problem; then, stop. Else, if the value of $L$ is smaller than 10 , add up $\varepsilon^{\prime}$ to every bound of the last previous range of $w_{i t}$, set $L=L+1$, and go back to Step 3. If the quantity of $L$ is greater than 10 , set $i=3-i$ and go back to Step 3 .
Figure 2 yields the flowchart of the intended heuristics algorithm.

\section{Cooperative game}

In this section, the problem is solved using the cooperative game as a strategy to respond to the production cost disruption. In this game, the supply chain members make their decision cooperatively. The cooperative game is a one-stage game and its fitness function is the sum of the fitness functions of all members. The solution method used to solve the problem and defined in this section is League Championship Algorithm (LCA) metaheuristic. In every cooperative game problem, a bargaining model divides the obtained profit among the members. The utilized bargaining model and LCA are briefly explained in the following.

\subsection{Bargaining model}

In the cooperative game, the obtained profit should be divided among the chain members using an appropriate bargaining model. In this paper, Nash equilibrium bargaining model is utilized [42]. If the total profits of the centralized part and the retailer in the cooperative and Stackelberg games are given by $\Pi_{C C P}^{*}, \Pi_{C R}^{*}, \Pi_{r}^{*}$, and $\Pi_{c p}^{*}$, respectively, and the gained profit in the cooperative game is denoted by $\Pi_{c}^{*}$; then, the optimal level for each part of the chain in the cooperative game is given by [53]:

$$
\begin{aligned}
& \Pi_{C R}^{*}=\frac{1}{2}\left(\Pi_{C}^{*}-\Pi_{c p}^{*}+\Pi_{r}^{*}\right), \\
& \Pi_{C C P}^{*}=\frac{1}{2}\left(\Pi_{C}^{*}+\Pi_{c p}^{*}-\Pi_{r}^{*}\right) .
\end{aligned}
$$

5.2. League Championship Algorithm (LCA)

LCA is among stochastic and population-based metaheuristic algorithms and is used for solving continuous optimization problems. It mimics the champion process in sport league. In addition to the nature, culture, politics, human, etc. as general sources of inspiration of various algorithms, the metaphor of sporting competitions has been used for the first time in LCA. In LCA, every solution array containing $n$ members plays a role as a sport team and in pairs in an artificial league and during multiple weeks. Broadly, LCA solves the problem using the following steps:

Step 1: Set $t=1$ (week index);

Step 2: Initialize league size $(L)$ and the number of seasons $(s)$. Then, generate $L$ number of solutions randomly. Every solution is considered as a team and is displayed as a $(1 \times n)$ array $(n$ is the number of variables of the intended problem). Fitness function of the $i$ th team $(i=1, \cdots, n)$ is $\left(f\left(x_{i}^{t}\right)\right)$ and considered as the best obtained solution for team $i$; 


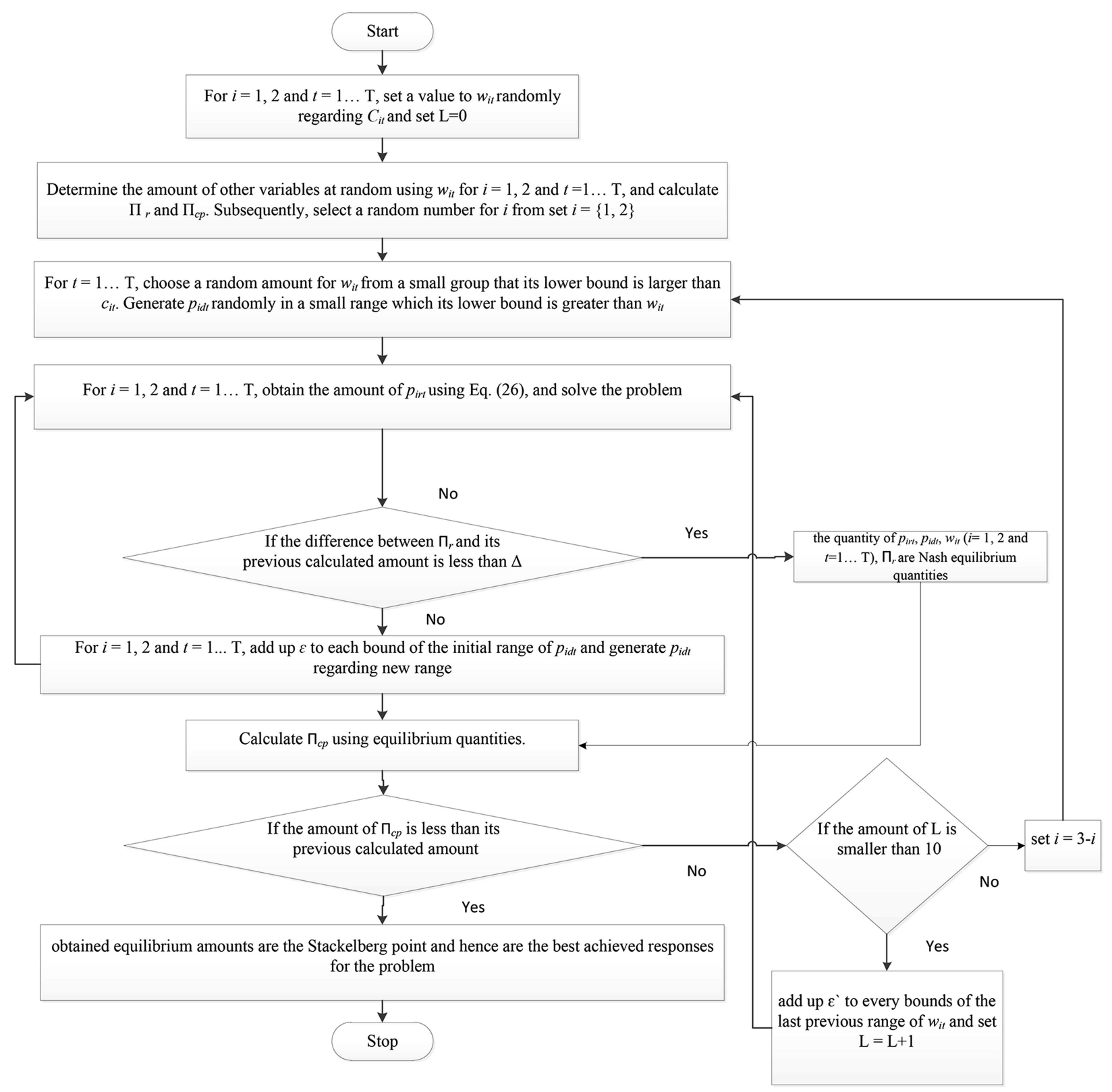

Figure 2. Flowchart of heuristic algorithm.

Step 3: As the teams play in pairs in an artificial league and during multiple weeks, obtain a league schedule utilizing single round-robin method which is used in real football leagues;

Step 4: In week $t$, the teams match in pairs and the winner of a match is determined stochastically with respect to the fitness function (playing strength) of the two following artificial teams. If teams $i$ and $j$ with formations (solutions) $x_{i}^{t}$ and $x_{j}^{t}$ and playing strengths $f\left(x_{i}^{t}\right)$ and $f\left(x_{j}^{t}\right)$, respectively, they play against each other in week $t$ and $\hat{f}$ is the ideal point; then, the expected value for the team $i^{\prime}$ s chance to beat team $j$ is calculated as follows:

$$
p_{i}^{t}=\frac{f\left(x_{j}^{t}\right)-\hat{f}}{f\left(x_{j}^{t}\right)+f\left(x_{i}^{t}\right)-2 \hat{f}} .
$$

To determine the winner, generate a number randomly in the range of $[0,1]$ if the generated number is less (greater) than or equal to $p_{i}^{t}$; then, team $i$ is the winner (loser) of the game. Choose the best obtained solution for team $i(i=1, \cdots, n)$ and display it as $B_{i}^{t}=\left[b_{i 1}^{t}, b_{i 2}^{t} \cdots b_{i n}^{t}\right]$;

Step 5: If $\bmod (t, L-1) \neq 0$ (is not equal to zero), go to Step (6), else, the season has ended, and player transfer between clubs should be conducted. Therefore, for team $i, i=1, \ldots, n$, create a set $M_{i}=$ 
$\left\{m \mid m \neq i, f\left(B_{t m}\right)<f\left(B_{t i}\right)\right\}$, and for $d=1, \ldots, n$, choose a random number from $[0,1]$. If this number is less than a threshold value Tr, Choose an index from $M_{i}$ randomly and update $b_{i d}^{t}$ by the value of $b_{m d}^{t}$. Afterwards, generate a new league schedule and then go to Step (6);

Step 6: If $t \geq S \times(L-1)$, LCA ends; else, go to Step 7;

Step 7: For team $i(i=1, \cdots, L)$, set up a new team formation. To assign a new formation to a team, SWOT decision matrix is utilized. In LCA, strengths and weaknesses of the team as internal criteria and threats and opportunities (strengths and weaknesses of the rival team) as external criteria should be analyzed. Broadly, one of the following equations obtains a new team formation:

$\mathrm{S} / \mathrm{T}$ equation :

$$
\begin{aligned}
x_{i d}^{t+1}= & b_{i d}^{t}+y_{i d}^{t}\left(\Psi_{1} r_{1 i d}\left(x_{i d}^{t}-x_{k d}^{t}\right)\right. \\
& \left.+\Psi_{1} r_{2 i d}\left(x_{i d}^{t}-x_{j d}^{t}\right)\right), \quad \forall d=1, \ldots, n,
\end{aligned}
$$

$\mathrm{S} / \mathrm{O}$ equation :

$$
\begin{aligned}
x_{i d}^{t+1}= & b_{i d}^{t}+y_{i d}^{t}\left(\Psi_{2} r_{1 i d}\left(x_{i d}^{t}-x_{k d}^{t}\right)\right. \\
& \left.+\Psi_{1} r_{2 i d}\left(x_{i d}^{t}-x_{j d}^{t}\right)\right) \quad \forall d=1, \ldots, n,
\end{aligned}
$$

$\mathrm{W} / \mathrm{T}$ equation :

$$
\begin{aligned}
x_{i d}^{t+1}= & b_{i d}^{t}+y_{i d}^{t}\left(\Psi_{1} r_{1 i d}\left(x_{i d}^{t}-x_{k d}^{t}\right)\right. \\
& \left.+\Psi_{2} r_{2 i d}\left(x_{j d}^{t}-x_{i d}^{t}\right)\right) \quad \forall d=1, \ldots, n,
\end{aligned}
$$

W/O equation :

$$
\begin{aligned}
x_{i d}^{t+1}= & b_{i d}^{t}+y_{i d}^{t}\left(\Psi_{2} r_{1 i d}\left(x_{k d}^{t}-x_{k d}^{t}\right)\right. \\
& \left.+\Psi_{2} r_{2 i d}\left(x_{j d}^{t}-x_{i d}^{t}\right)\right) \quad \forall d=1, \ldots, n,
\end{aligned}
$$

where $d$ is dimension index and $r_{1 i d}$ and $r_{2 i d}$ are uniform random numbers in $[0,1] . B_{i}^{t}=\left\{b_{i 1}^{t}, b_{i 2}^{t}, \cdots, b_{i n}^{t}\right\}$ is the best obtained solution for team $i$ until week $t$. $\Psi_{1}$ and $\Psi_{2}$ are coefficients of retreat and approach, respectively. $Y_{i}^{t}=\left(y_{i 1}^{t}, y_{i 2}^{t}, \cdots, y_{i n}^{t}\right)$ is a binary change array in which $y_{i d}^{t}$ is the binary change variable. In this array, the number of ones is equal to $q_{i}^{t}$. The number of changes in $B_{i}^{t}$ is calculated as follows:

$$
\begin{aligned}
q_{i}^{t}= & {\left[\frac{\ln \left(1-\left(1-\left(1-p_{c}\right)^{n-q_{0}+1}\right) r\right)}{\ln \left(1-p_{c}\right)}\right]+q_{0}-1, q_{i}^{t} } \\
& \in\left\{q_{0}, q_{0}+1, \ldots, n\right\},
\end{aligned}
$$

where $r$ is the stochastic variable in $[0,1]$ and $p_{c}\left(p_{c}<\right.$ $\left.1, p_{c} \neq 0\right)$ is the control parameter. The least change determined in the artificial play analysis process is denoted by $q_{0}$. After simulating the changes, using Eq. (34), $q_{i}^{t}$ number of elements is selected at random from $B_{i}^{t}$ and their amount is changed using one of Eqs. (30)(33). After assigning new formations, set $t=t+1$ and go back to Step $4[54,55]$.

\section{Numerical example}

As mentioned before, the case of this paper is IKCO wherein IKCO, as the manufacturer facing disruption, and Saipa along with free market as the other manufacturer and common retailers have established the intended dual-channel supply chain, respectively. In this section, a numerical example is used for solving the problem that the required data has been assigned by consulting IKCO staff members. The example considers the years 2011 and 2012 as the no-disruption and disruption years, respectively. According to the staff's statements, IKCO proceeds to hold a meeting to change the selling price of its products every four months on average. Therefore, each year has been divided into three periods. Peugeot 206 and Brilliance H230 with nearly equal prices have been selected as the products of IKCO and Saipa, respectively. The required data for this section taken from IKCO are given in Table 1.

To solve the Stackelberg game problem, the represented heuristic algorithm is implemented in MatLab (R2012B) Software. The assumed ranges for $w_{i t}$ and $p_{i d t}$ in Million-Toman (currency of Iran) units are as follows:

$$
\begin{aligned}
& p_{1 d t-\min }=(16,16,16,20,26,31), \\
& p_{1 d t-\max }=(17,17,17,22,28,34), \\
& p_{2 d t-\min }=(16,16,16,17,17,17),
\end{aligned}
$$

and :

$$
p_{2 d t-\max }=(17,17,17,19.05,19.5,19.5) \text {. }
$$

The heuristic algorithm and LCA have solved the problem using the numerical example, as shown in Table 1. Tables 2 and 3 represent the obtained results.

The profits are determined using the Nash equilibrium members' bargaining model as follows:

$$
\pi_{C R}^{*}=221,938,852,457, \quad \pi_{C C P}^{*}=587,068,622,106 .
$$

Remark 1: The comparisons reveal that the cooperative game problem is more profitable for all members than the Stackelberg game problem. The reasons for the higher profit of the cooperative game problem are the production quantity and the demand level. The results clarify that the levels of both $Q_{1 t}$ and $Q_{2 t}$ in Table 2 are greater than those given in Table 3 . It is shown that in the cooperative game scenario, the 
Table 1. Data acquired from IKCO.

$$
\begin{aligned}
& c_{i 1}=[12,000,00012,000,000] \quad \mu=30,000 \quad b_{d}=\left[\begin{array}{ll}
100,000 & 100,000
\end{array}\right] \quad h_{r}=100,000 \\
& g=\left[\begin{array}{ll}
0.00005 & 0.0002
\end{array}\right] \quad b_{r}=100,000 \quad \theta_{r}=\left[\begin{array}{ll}
0.3 & 0.1
\end{array}\right] \quad \varepsilon_{1 j t} \sim N(0,10) \\
& h_{d}=[100,000100,000] \quad \theta_{d}=\left[\begin{array}{ll}
0.45 & 0.15
\end{array}\right] \quad \Delta=1 \% \quad \varepsilon_{2 j t} \sim N(0,6) \\
& r_{0}=[12,800,000 \quad 12,800,000] \quad T=6 \quad \alpha=0.3 \\
& \varphi=\left[\begin{array}{ll}
0 & 0 \\
0 & 0 \\
0 & 0 \\
1 & 1 \\
1 & 1 \\
1 & 1
\end{array}\right] \quad \beta_{d}=\left[\begin{array}{cc}
0.0012 & 0.00134 \\
0.00089 & 0.00166 \\
0.00083 & 0.00156 \\
0.00087 & 0.001806 \\
0.00065 & 0.0014 \\
0.00075 & 0.00085
\end{array}\right] \quad \beta_{r}=\left[\begin{array}{cc}
0.00168 & 0.00095 \\
0.00172 & 0.00095 \\
0.0017 & 0.00088 \\
0.00176 & 0.001 \\
0.00115 & 0.00082 \\
0.00072 & 0.0009
\end{array}\right] \quad y_{d}=\left[\begin{array}{cc}
0.00049 & 0.0004 \\
0.0008 & 0.00008 \\
0.00074 & 0.00008 \\
0.00085 & 0.00008 \\
0.0005 & 0.00008 \\
0.00045 & 0.00009
\end{array}\right]
\end{aligned}
$$

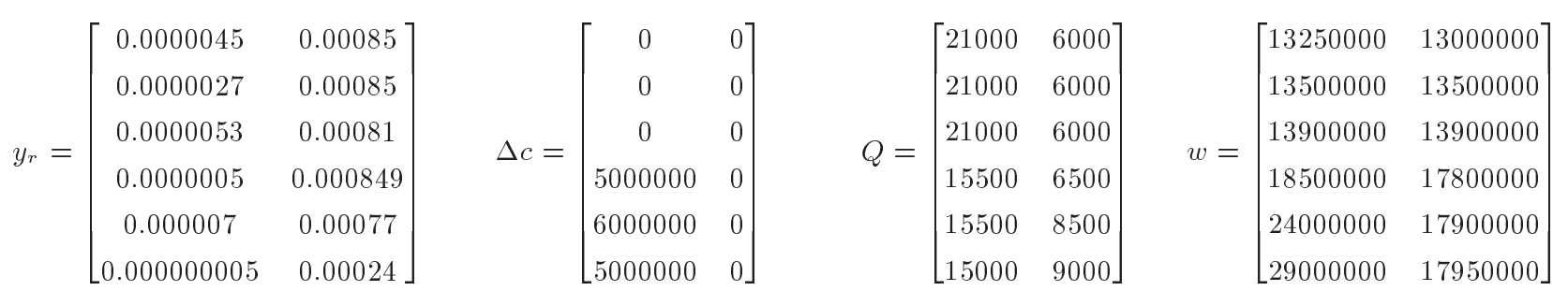

Table 2. Obtained results for the Stackelberg problem.

\begin{tabular}{ccccccc}
\hline Period & $\mathbf{1}$ & $\mathbf{2}$ & $\mathbf{3}$ & $\mathbf{4}$ & $\mathbf{5}$ & $\mathbf{6}$ \\
\hline$w_{1 t}$ & $13,169,649$ & $13,178,360$ & $13,181,144$ & $18,199,910$ & $24,184,222$ & $29,027,680$ \\
$w_{2 t}$ & $13,371,213$ & $13,549,644$ & $13,665,012$ & $14,353,282$ & $14,397,907$ & $14,654,882$ \\
$p_{1 d t}$ & $16,460,272$ & $16,560,185$ & $16,769,966$ & $21,335,481$ & $27,833,529$ & $32,782,388$ \\
$p_{2 d t}$ & $16,103,801$ & $16,114,036$ & $16,797,380$ & $18,022,308$ & $18,417,229$ & $19,049,395$ \\
$p_{1 r t}$ & $17,598,323$ & $17,428,245$ & $17,202,854$ & $21,256,310$ & $28,067,053$ & $33,912,553$ \\
$p_{2 r t}$ & $16,397,983$ & $16,503,021$ & $16,732,648$ & $18,062,517$ & $18,353,116$ & $18,207,555$ \\
$q_{1 r t}$ & 7,678 & 7,536 & 7,053 & 5,848 & 5,047 & 4,260 \\
$q_{2 r t}$ & 1,841 & 1,856 & 2,086 & 4,838 & 3,503 & 3,061 \\
$q_{1 d t}$ & 14,206 & 14,061 & 14,551 & 11,709 & 11,011 & 11,029 \\
$q_{2 d t}$ & 5,003 & 5,021 & 4,333 & 5,420 & 6,938 & 7,418 \\
$Q_{1 t}$ & 21,884 & 21,297 & 21,604 & 17,557 & 16,058 & 15,289 \\
$Q_{2 t}$ & 6,844 & 6,877 & 6,419 & 10,258 & 10,441 & 10,479 \\
\hline Total profit & \multicolumn{7}{c}{$783,114,480,012$} \\
\hline Retailer's profit & $208,992,355,183$ & cent. part's profit \\
\hline
\end{tabular}


Table 3. Obtained results for the cooperative problem.

\begin{tabular}{|c|c|c|c|c|c|c|}
\hline Period & 1 & 2 & 3 & 4 & 5 & 6 \\
\hline$w_{1 t}$ & $13,744,757$ & $13,757,778$ & $13,893,086$ & $18,760,960$ & $24,983,642$ & $29,297,395$ \\
\hline$w_{2 t}$ & $13,181,421$ & $13,635,705$ & $13,921,629$ & $14,652,660$ & $14,837,604$ & $14,980,727$ \\
\hline$p_{1 d t}$ & $17,065,314$ & $17,194,105$ & $17,286,475$ & $22,285,889$ & $28,869,059$ & $34,385,837$ \\
\hline$p_{2 d t}$ & $16,132,030$ & $16,293,663$ & $16,826,085$ & $17,687,272$ & $18,427,982$ & $19,470,202$ \\
\hline$p_{1 r t}$ & $16,906,758$ & $16,908,651$ & $17,101,218$ & $21,138,203$ & $26,499,352$ & $34,083,534$ \\
\hline$p_{2 r t}$ & $16,738,134$ & $16,930,685$ & $17,003,686$ & $19,167,620$ & $19,204,443$ & $19,312,219$ \\
\hline$q_{1 r t}$ & 9,648 & 9,314 & 7,829 & 8,413 & 9,021 & 5,998 \\
\hline$q_{2 r t}$ & 1,995 & 2,026 & 2,031 & 4,206 & 3,340 & 2,857 \\
\hline$q_{1 d t}$ & 13,777 & 13,874 & 14,342 & 11,785 & 10,971 & 10,959 \\
\hline$q_{2 d t}$ & 5,548 & 5,644 & 4,906 & 7,783 & 8,108 & 8,059 \\
\hline$Q_{1 t}$ & 23,425 & 23,188 & 22,171 & 20,198 & 19,992 & 16,957 \\
\hline$Q_{2 t}$ & 7,543 & 7,670 & 6,937 & 11,989 & 11,448 & 10,916 \\
\hline
\end{tabular}

demand in four selling channels is higher than that in the Stackelberg game scenario. As a result, the achieved profit for each member in the cooperative game scenario is higher than that in the Stackelberg game scenario.

\section{Sensitivity analysis}

In this section, the sensitivity of fitness function to the main parameters such as $\beta_{\text {irt }}, y_{\text {irt }} \alpha$, and $\mathrm{g}$ is analyzed. According to the demand function, the demand quan- tity and the fitness amount are lower with gradual increase in $\beta_{\text {irt }}$. In addition, the demand function demonstrates that the amount of profit decreases as $y_{\text {irt }}$ increases. Outcomes of the conducted experiments have confirmed the mentioned results and because of their clarity, they have not been represented in the paper.

The main parameters that are analyzed in this section are the reference price-related parameters. Firstly, $\alpha$ is analyzed. The acquired results for $r_{i t}$ from the conducted experiments are given in Table 4 for $0<\alpha<1$.

Table 4. Obtained results for reference price $\left(r_{i t}\right)$.

\begin{tabular}{|c|c|c|c|c|c|c|c|c|c|}
\hline \multicolumn{10}{|c|}{ First manufacturer (IKCO) } \\
\hline$\alpha$ & 0.1 & 0.2 & 0.3 & 0.4 & 0.5 & 0.6 & 0.7 & 0.8 & 0.9 \\
\hline$t=1$ & 12920000 & 12920000 & 12920000 & 12920000 & 12920000 & 12920000 & 12920000 & 12920000 & 12920000 \\
\hline$t=2$ & 15877314 & 15921438 & 15291072 & 14974242 & 14516418 & 14139994 & 13813416 & 13500223 & 13136833 \\
\hline$t=3$ & 16303640 & 16607282 & 16208185 & 15834916 & 15370783 & 15007139 & 14555638 & 14087691 & 13426942 \\
\hline$t=4$ & 16321540 & 16659900 & 16539347 & 16209623 & 15836194 & 15697307 & 15110087 & 14625369 & 13689432 \\
\hline$t=5$ & 20607783 & 19847676 & 19692957 & 18656123 & 18414456 & 17748913 & 16690467 & 15870418 & 14353023 \\
\hline$t=6$ & 26415669 & 25956267 & 24592661 & 23599193 & 22567458 & 21406731 & 19767484 & 18132018 & 15543436 \\
\hline \multicolumn{10}{|c|}{ Second manufacturer (Saipa) } \\
\hline$\alpha$ & 0.1 & 0.2 & 0.3 & 0.4 & 0.5 & 0.6 & 0.7 & 0.8 & 0.9 \\
\hline$t=1$ & 12920000 & 12920000 & 12920000 & 12920000 & 12920000 & 12920000 & 12920000 & 12920000 & 12920000 \\
\hline$t=2$ & 15214048 & 15078214 & 14711695 & 14769213 & 14424970 & 13867327 & 13618067 & 13356424 & 13068008 \\
\hline$t=3$ & 15624712 & 15744582 & 15450808 & 15627674 & 15338377 & 14603882 & 14287626 & 13833394 & 13314922 \\
\hline$t=4$ & 15763690 & 15968766 & 15797394 & 16238165 & 15916341 & 15129290 & 14781251 & 14266210 & 13595785 \\
\hline$t=5$ & 17845780 & 17275240 & 17374451 & 16925230 & 16795609 & 16152735 & 15596856 & 14971128 & 13996102 \\
\hline$t=6$ & 18183455 & 17802268 & 18010545 & 17505284 & 17420788 & 17013900 & 16345420 & 15678260 & 14355978 \\
\hline
\end{tabular}




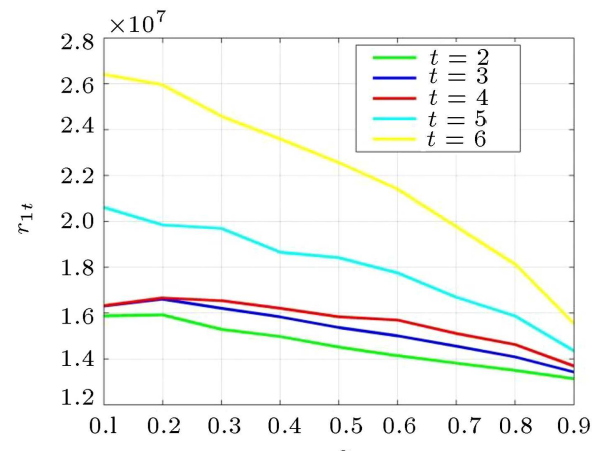

$\alpha$
$(\mathrm{a})$

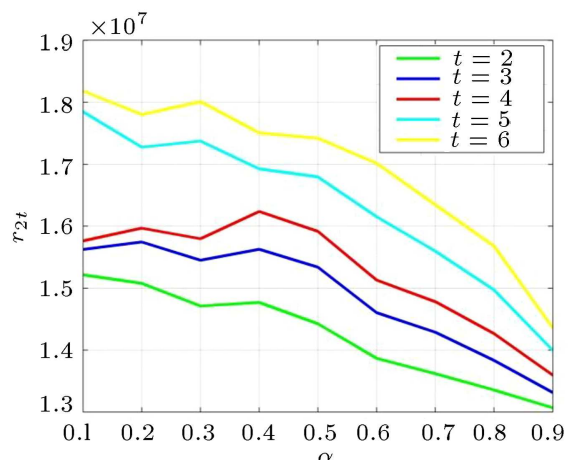

(b)

Figure 3. Effects of $\alpha$ on $a=r_{1 t}$, and $b=r_{2 t}$.

For the sake of analysis convenience, the obtained results are depicted in Figure 3 . Figure 3 shows that the smaller value of $\alpha$ causes $r_{i t, i=1,2}$ to be influenced in the higher degree by $p_{i(t-1)}$. This effect will cause a decrease in the gap between $p_{i t}$ and $r_{i t}$. In Figure 3(a), due to the disruption occurring in Periods 5 and 6 , curves of $t=5$ and $t=6$ illustrate the considerable decrease in $r_{1 t}$ that results in increase in $\alpha$. The smaller value of $\alpha$ is the reason why $p_{1(t-1)}$ affects significantly $r_{1 t}$, raises the quantity of $r_{1 t}$, and subsequently, reduces the difference between $r_{1 t}$ and $p_{1 t}$.

Therefore, decrease in the demand occurs to some degree. As a result, disruption has less destructive effects on the supply chain. Regarding $\alpha$ as the memory parameter, the achieved results are explained in Remark 2.

Remark 2: When the disruption occurs, the demand quantity for products with short-time memory, i.e., lower value of $\alpha$, decreases upon increase in $p$. As a result, the demand can be adapted to the situation effectively. However, substantial analyses about increase in the selling price of a product with long-time memory, i.e., higher amount of $\alpha$, should be conducted and the selling price should be determined to be as low as possible due to the remarkable impact of $r_{t-1}$ on $r_{t}$.

This result can be verified considering the quantity of $r_{i t}$ when $\alpha$ is allocated higher value in Periods 5 and 6 as Figure 3(a) illustrates.

In this section, the effects of $\alpha, g_{1}$, and $g_{2}$ on the fitness function in both cooperative and Stackelberg games are considered analytically. In this analysis, there are 10 steps and, in each step, the values of $\alpha$ and $\left(g_{2}-g_{1}\right)$ are determined increasingly at a rate of 0.1 . Obtained results are depicted in Figures 4-6.

In Figures 4 and 5 (Stackelberg-related ones), the maximum level of the fitness function is obtained in the second step (0.2 increase). It may be possible to explain the mentioned result as seen in Table 4 and Figure 3(a) and (b). It is evident that in most of the periods, maximum level of $r_{i t, i=1,2}$ is obtained

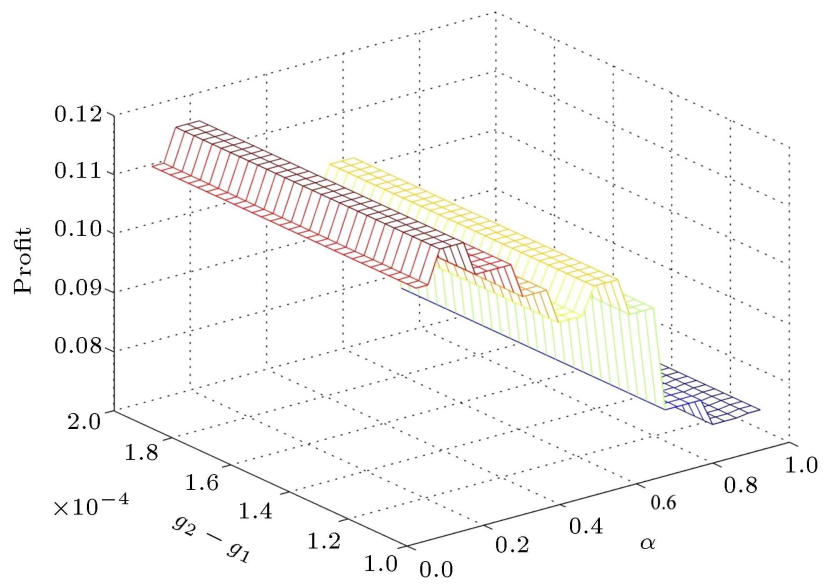

Figure 4. Profits under retailers (free market) and Stackelberg game scenario.

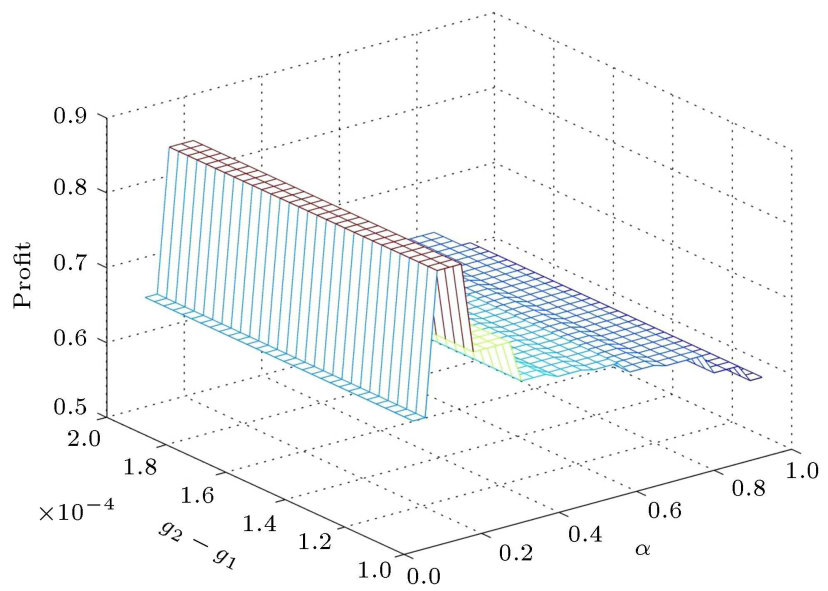

Figure 5. Profits under centralized part (Competition Committee) and Stackelberg game scenario.

when $\alpha=0.2$. This result illustrates that following a 0.2 increase, the difference between $r_{i t}$ and $p_{i t}$ is at the lowest level in most periods. Thus, if the values of $\alpha$ and $\left(g_{2}-g_{1}\right)$ increase to 0.2 , maximum profit for each chain member is achieved in the Stackelberg game. Broadly, the obtained results demonstrate that the lower values of the corresponding parameters result 
Table 5. Total profits of games in each step.

\begin{tabular}{ccccccccc}
\hline Ratio & $\mathbf{1}$ & $\mathbf{2}$ & $\mathbf{3}$ & $\mathbf{4}$ & $\mathbf{5}$ & $\mathbf{6}$ & $\mathbf{7}$ & $\mathbf{8}$ \\
\hline Stack. & $7.55 \mathrm{E}+11$ & $9.53 \mathrm{E}+11$ & $8.25 \mathrm{E}+11$ & $7.63 \mathrm{E}+11$ & $7.50 \mathrm{E}+11$ & $7.51 \mathrm{E}+11$ & $7.28 \mathrm{E}+11$ & $7.06 \mathrm{E}+11$ \\
Coop. & $8.56 \mathrm{E}+11$ & $8.56 \mathrm{E}+11$ & $8.52 \mathrm{E}+11$ & $8.52 \mathrm{E}+11$ & $8.51 \mathrm{E}+11$ & $8.3 \mathrm{E}+11$ & $8.24 \mathrm{E}+11$ & $8.1 \mathrm{E}+11$ \\
Ratio & 0.9 & 1 & & & & & & \\
Stack. & $6.74 \mathrm{E}+11$ & $6.51 \mathrm{E}+11$ & & & & & & \\
Coop. & $7.9 \mathrm{E}+11$ & $7.8 \mathrm{E}+11$ & & & & & & \\
\hline
\end{tabular}

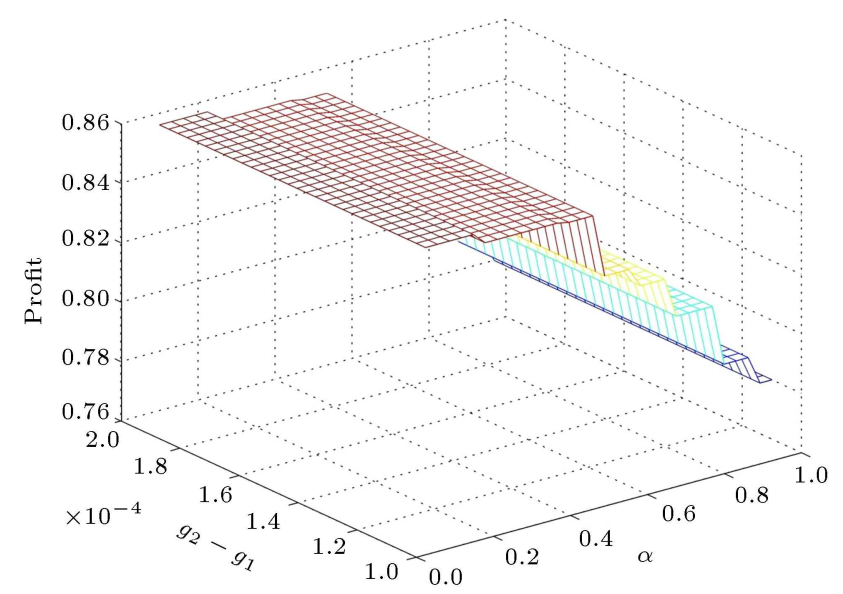

Figure 6. Profit under cooperative game scenario.

in the higher demand level for the product and profit as well. Comparison between Figures (4) and (5) reveals that in the Stackelberg scenario, the value of $\Pi_{s c}$ decreases in a great slop after Step 2. In Figure 4, $\Pi_{r}$ has a negative great slop in Step 7 . Since the free market has two selling channels and only the first channel $(i=1)$ has disrupted, the mentioned channel has lower demand than the relevant product's direct channel demand. Therefore, it can be declared that the retail channel of IKCO product is more resistant than its direct channel. The reason why Competition Committee has imposed substantial losses is that the largest percentage of the total market demand has been allocated to IKCO and the disruption has caused the gap between $r_{1 t}$ and $p_{1 t}$ to increase and $q_{1 t}$ to decrease significantly as well. Furthermore, Table 4 shows that the gap between $r_{2 t}$ and $p_{2 t}$ tends to increase slowly with time; hence, $\Pi_{2}$ has somewhat decreased. For these reasons, Competition Committee has imposed considerable losses as the product has long-time memory and the disruption occurs.

To compare the Stackelberg and cooperative scenarios, Table 5 demonstrates the total profit of the dual-channel supply chain. Figure 6 depicts that there is a considerable decrease in Step 7. This obtained result and also numbers in Table 5 confirm the better performance of the cooperative game rather than the Stackelberg game. Remark (3) yields the main obtained results.
Remark 3: In case of disruption, the cooperative game is resistant to products of any kinds of memory and is profitable for all members of the chain compared with the Stackelberg game. In the intended case study, considering automobile as a product with longtime memory (since the quantity of $\alpha$ ranges between $[0.3,0.5]$ according to statements of IKCO staff), it is suggested that Competition Committee will utilize the cooperative game as an efficient strategy to counteract the effects of the sanction-induced disruption against IKCO.

\subsection{Optimal level for the wholesale price in the case study}

In this section, the optimal wholesale price for the second manufacturer of the case study, Saipa, is analyzed. For this purpose, the quantity of $w_{2 t}$ for each $t=4,5,6$ (disruption periods) is orderly analyzed in different ranges in Million Toman units: $\{(15,16)$, $(16,17),(17,18)\},\{(15,17),(17,19),(19,21),(21$, $23)\}$, and $\{(14,17),(17,20),(20,23),(23,26),(26$, $28)\}$. Figure 7 depicts the obtained results for the profit of Competition Committee. The main achieved result in Figure 7 is that in a competitive market, the moment a manufacturer increases the selling price of its product, it would not be an appropriate strategy for its competitors to raise their product's selling price approximately equal to the intended product's selling price. To maximize the competitors' profit in such a situation, they should conduct some profound analyses and then, determine the optimal selling price. Figure 7 yield the optimal level for $w_{2 t}$ given in Table 6 .

In such a supply chain with a disrupted manufacturer, sometimes, increasing the selling price of the other manufacturer approximately to as high as the selling price of the disrupted manufacturer is not only detrimental to the intended manufacturer but also profitable to the other chain members. In Figure 7 (a) and (b), if Competition Committee selects $w_{2 t}$ from [19, 21] in the second disruption period, the free market

Table 6. Optimal amount of $w_{2 t}$ in disruption periods.

\begin{tabular}{cccc}
\hline Disruption period & $\mathbf{1}$ & $\mathbf{2}$ & $\mathbf{3}$ \\
\hline Cooperative & {$[16,17]$} & {$[17,19]$} & {$[17,20]$} \\
Stackelberg & {$[16,17]$} & {$[17,19]$} & {$[20,23]$} \\
\hline
\end{tabular}




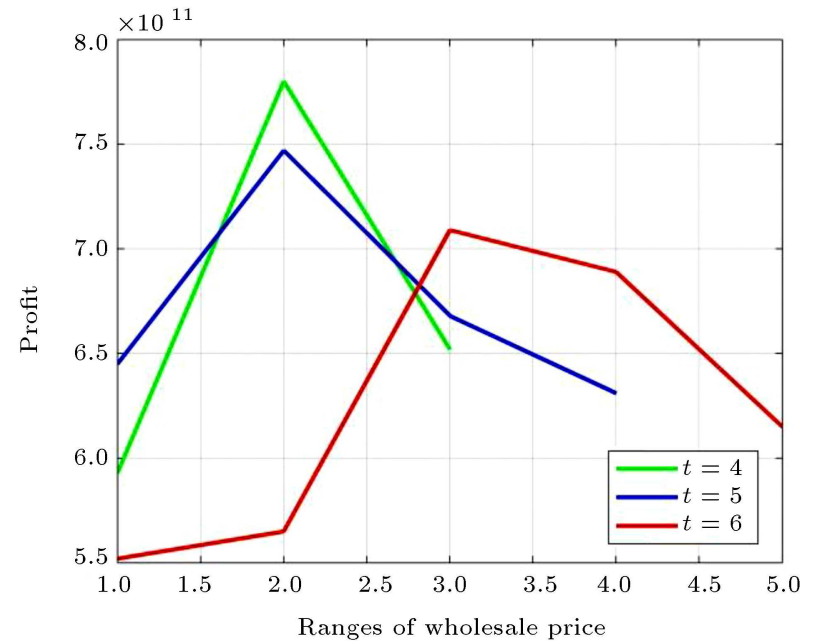

(a)

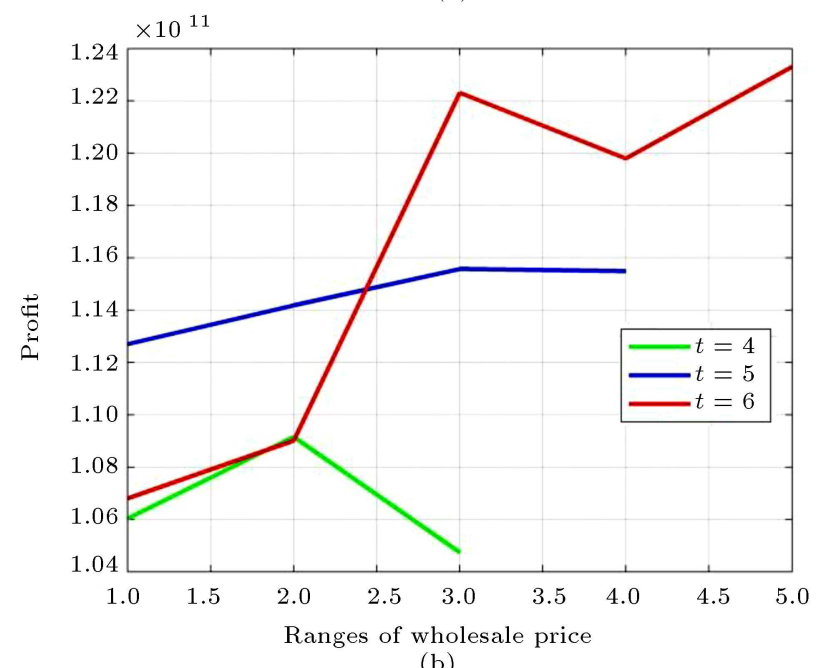

(b)

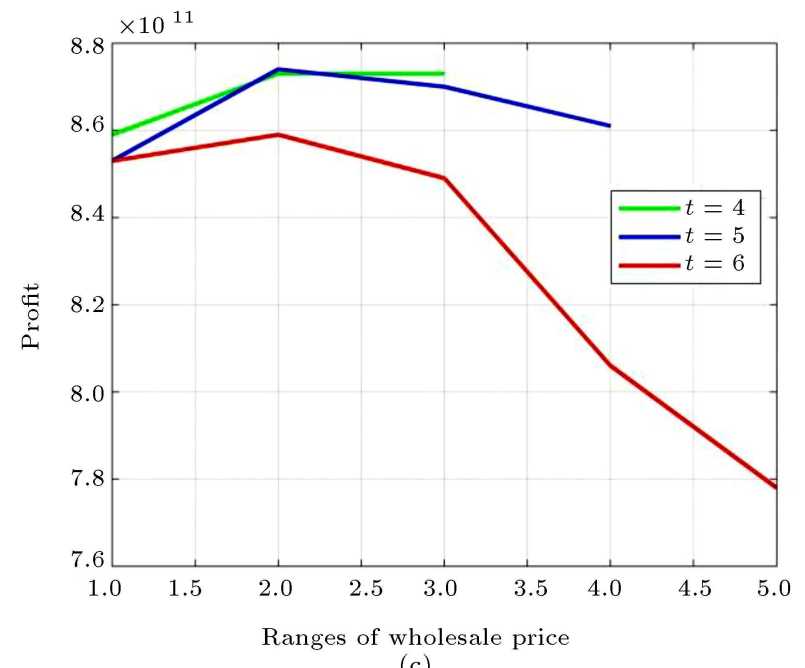

(c)

Figure 7. Effects of $w_{2 t}$ on profits of $a=$ Centralized part, $b=$ retailer, and $c=$ cooperative game.

allocates more profit than the case of being $w_{2 t}$ in $[17,19]$; however, unlike the free market, Competition Committee gains lower profit than the optimal range $[17,19]$. Moreover, in the third disruption period, if
Competition Committee selects $w_{2 t}$ in $[26,28]$ with the goal of gaining more profit, based on Figure 7(a) and (b), the free market earns more profit than the other defined cases, while Competition Committee does not achieve its maximal profit level.

\section{Management insights}

The most important management notifications obtained through this study are given as follows:

1. In case of disruption, products with long-term memory are more susceptible to risk than those with short-term memory;

2. To shield demand against high volatility and variation, in-depth analyses should be carried out to determine the optimal selling price;

3. According to the cooperative game, presenting products with any kinds of memory may represent a proper strategy to respond to the disruption due to its remarkable resilience against the disruption as well as its profitability for all members of the supply chain;

4. Upon increasing the selling price for a manufacturer, other competitors should conduct deep analyses to determine the best response of their selling price.

\section{Conclusion}

This study considered the sanctions that had been imposed against IKCO analytically. For this purpose, it considered a semi-centralized dual-supply chain that comprised two manufacturers (IKCO and Saipa) and a retailer (free market). Each manufacturer had two selling channels: retail and direct channels. The stochastic demand of each selling channel was dependent on the reference price and other channels' selling prices. One manufacturer (IKCO) suffered disruption in production and costs. It was assumed that the intended manufacturer lost the demand insignificantly due to its higher popularity in the market. To solve the problem, Stackelberg game was used and the existing price competition among the selling channels was the reason behind the application of the Nash equilibrium in the second stage of the Stackelberg game. Moreover, cooperative game was introduced as a strategy for disruption management. The results of solving the problem based on the data collected from IKCO demonstrated that the cooperative game was more profitable for the all chain members due to increase in the demand within all channels and subsequently, all manufacturers' production level increased. Results of the experiments indicated that the supply chains that produced products with a short-time memory struggled 
with disruptions resiliently, illustrating that the cooperative game was beneficial to products of any types of memory, e.g., long-time and short-time memories under disruption. According to the mentioned results, the cooperative game could be used to manage the disruption. The results represented an optimal range of the wholesale prices of the second manufacturer (Saipa) in the disruption periods.

As stated earlier, this study addressed a realworld problem. In terms of the nature of the intended problem, the semi-centralized supply chain has been introduced for the first time in the supply chain literature. In addition to the introduction of the semicentralized supply chain concept, the main contribution of the study is to analyze the effect of the reference price on the real-world disrupted supply chain problem. The reference price has a determinant role in the resilience of the supply chain against the disruptions. In a Stackelberg game, the longer the product's memory time is, the greater the effects of the disruption on the supply chain will be. However, the supply chain was resilient regardless of the memory type in the cooperative game. The proposed method with support of the experimental results demonstrated that the memory type of the product was effective in the degree of resilience in the Stackelberg game. As a result, the memory type could be considered as one of the influential factors in determining power structure and disruption management, as well.

The most significant limitation of the study was that upon analyzing the second stage of the manufacturer's problem in the Stackelberg scenario, determining the wholesale price was rather impossible so that the heuristics algorithm had to be utilized. Proposing an appropriate approach with the aim of solving this issue could be regarded as a future opportunity. One suggestion for this matter is considering a uniform distribution for the stochastic demand function in order to make Expression (23) simpler. Additionally, in the study, the problem involving only one product of IKCO and one product of Saipa required a less complicated model. Considering the other products of IKCO and Saipa including their own brands as well as foreign brands and analyzing their effects on the profit of IKCO as well as taking into consideration the impacts of the exchange rate variations on the profit function might yield a more proper insight into IKCO. Another possible research opportunity may be taking into account other common types of existing disruption in the literature like disruptions in supply, demand, and demand and production cost simultaneously.

Last but not least, the main objective of this research mainly considers Iran's status under sanction years. Over these years, Iran's industry has experienced economic depressions. Events of these years point to the necessity of conducting a large number of studies on Iran's industry. This issue can be regarded as the considerable opportunity for future researches as well.

\section{References}

1. Tao, J. and Zhao, S. "The mode of different price in dual-channel supply chain", International Journal of $u$ - and e-Service, Science and Technology, 7, pp. 133144 (2014).

2. Sana, S.S., Chedid J.A., and Navarro, S. "A three layer supply chain model with multiple suppliers, manufacturers and retailers for multiple items", Appl. Math. Comput., 229, pp. 139-150 (2014).

3. Modak, N.M., Panda, S., and Sana, S.S. "Two-echelon supply chain coordination among manufacturer and duopolies retailers with recycling facility", Int. $J . A d v$. Manuf. Technol., 87, pp. 1531-1546 (2016).

4. Modak, N.M., Panda, S., and Sana, S.S. "Threeechelon supply chain coordination considering duopolistic retailers with perfect quality products", Int. J. Prod. Econ., 182, pp. 564-578 (2016).

5. Sana, S.S., Herreva-Vidal, G., and Acevedo-Chedid, J. "Collaborative model on the agro-industrial supply chain of cocoa", Cybernetics and Systems: An International Journal, 48, pp. 325-347 (2017).

6. Modak, N.M., Modak, N., Panda, S., et al. "Analyzing structure of two-echelon closed-loop supply chain for pricing, quality and recycling management", J. Clean. Prod., 171, pp. 512-528 (2018).

7. Roy, A., Sana, S.S. and Chaudhuri, K. "Optimal pricing of competing retailers under uncertain demanda two layer supply chain model", Ann. Oper. Res., 260, pp. 481-500 (2018).

8. Tsay, A. and Agrawal, N. "Channel conflict and coordination in the E-commerce age", Prod. Oper. Manag., 13, pp. 93-110 (2004).

9. Mukhopadyay, S.K., Zhu, X., and Yue, X. "Information sharing of value-adding retailer in a mixed channel hi-tech supply chain", J. BUS. RES., 61, pp. 950-958 (2006).

10. Yan, R. "Profit sharing and firm performance in the manufacturer-retailer dual channel supply chain", Electronic Commerce Research, 8, pp. 155-172 (2008).

11. Chen, T.H. "Effects of the pricing and cooperative advertising policies in a two-echelon dual-channel supply chain", Comput. Ind. Eng., 87, pp. 250-259 (2015).

12. Panda, S., Modak, N.M., Sana, S.S., et al. "Pricing and replenishment policies in dual-channel supply chain under continuous unit cost decrease", Appl. Math. and Comp., 256, pp. 913-929 (2015).

13. Cai, G., Zhang, ZG., and Zhang, M. "Game theoretical perspectives on dual-channel supply chain competition with price discounts and pricing schemes", Int. J. Prod. Econ., 117, pp. 80-96 (2009). 
14. Cai, G. "Channel selection and coordination in dualchannel supply chain", J. Retailing, 86, pp. 22-36 (2010).

15. Yan, R. and Pei, Z. "Information asymmetry, pricing strategy and firm's performance in the retailer-multichannel manufacturer supply chain", Journal of Business Research, 64, pp. 377-384 (2011).

16. Cao, E., Wan, C., and Lai, M. "Coordination of a supply chain with one manufacturer and multiple competing retailers under simultaneous demand and cost disruptions", Int. J. Prod. Econ., 141, pp. 425$433(2013)$

17. Modak, N.M., Panda, S., Sana, S.S., et al. "Corporate social responsibility, coordination and profit distribution in a dual-channel supply chain", Pacific Science Review, 16, pp. 235-249 (2014).

18. Matsui, K. "When should a manufacturer set its direct price and wholesale price in dual-channel supply chain?", Eur. J. Oper. Res., 258, pp. 501-511 (2016).

19. Li, B., Zhu, M., Jiang, Y., et al. "Pricing policies of a competitive dual-channel green supply chain", $J$. Clean. Prod., 112, pp. 2029-2042 (2016).

20. Li, B., Hou, P., Chen, P., et al. "Pricing strategy and coordination in a dual-channel supply chain with a risk-averse retailer", Int. J. Prod. Econ., 178, pp. 154168 (2016).

21. Liu, M., Cao, E., and Salifou, C.K. "Pricing strategies of a dual-channel supply chain with risk aversion", Transp. Res. E., 90, pp. 108-120 (2016).

22. Wang, L., Song, H., and Wang, Y. "Pricing and service decisions of complementary products in a dual-channel supply chain", Comput Ind Eng, 105, pp. 223-233 (2017).

23. Xu, J., Qi, Q., and Bai, Q. "Coordinating a dualchannel supply chain with price discount contracts under carbon emission capacity regulation", Appl. Math. Model., 56, pp. 449-468 (2018).

24. Modak, N.M. and Kelle, P. "Managing a dual-channel supply chain under price and delivery-time dependent stochastic demand", Eur. J. Oper. Res., 272, pp. 147161 (2019).

25. Dan, B., Xu ,G., and Liu, C. "Pricing policies in a dual-channel supply chain with retail services", Int. $J$. Prod. Econ., 139, pp. 312-320 (2011).

26. Zhao, J., Hou, X., Guo, Y., et al. "Pricing policies for complementary products in a dual-channel supply chain", Appl. Math. Model., 49, pp. 437-451 (2017).

27. Qi, X., Bard, J.F., and Yu, G. "Supply chain coordination with demand disruptions", Omega, 32, pp. 301-312 (2004).

28. Xiao, TJ., Qi, X., and Yu, G. "Coordination of supply chain after demand disruptions when retailers compete", Int. J. Prod. Econ., 109, pp. 162-179 (2007).

29. Changchao, H., Gang, Y., Song, W., et al. "Disruption management for supply chain coordination with exponential demand function", Acta. Math. Sci., 26(B), pp. 655-669 (2006).
30. Chen, K. and Zhang, P. "Disruption management for a dominant retailer with constant demand-stimulating service cost", Comput. Ind. Eng., 61, pp. 936-946 (2011).

31. Huang, Y. and Wang, Z. "Demand Disruptions, pricing and production decisions in a closed loop supply chain with technology licensing", J. Clean. Prod., 191, pp. 248-260 (2018).

32. Hou, J., Zeng, A.Z., and Zhao, L. "Coordination with a backup supplier through buy-back contract under supply disruption", Transp. Res. E: Logistics and Transportation Review, 46, pp. 881-895 (2010).

33. Zhu, A.X. "Dynamic replenishment, production and pricing decisions in the face of supply disruption and random price-sensitive demand", Int. J. Prod. Econ., 146, pp. 612-619 (2013).

34. Kumar, M., Basu, P., and Avittathur, B. "Pricing and sourcing strategies for competing retailers in supply chains under disruption risk", Comput Ind Eng, 265, pp. 533-543 (2018).

35. Xu, M., Qi, X., Yu, G., et al. "Coordinating dyadic supply chain when production costs are disrupted", IIE Transactions, 38, pp. 765-775 (2006).

36. Xiao, J., Yu, G., Sheng, Z.H., et al. "Coordination of a supply chain with one-manufacturer and two-retailers under demand promotion and disruption management decisions", Ann. Oper. Res., 135, pp. 87-109 (2005).

37. Dongchuan, X., Hong, C., and Lai, W. "How to coordinate integrated supply chain when demand and cost disruptions occur simultaneously", Management Science and Engineering, 9, pp. 14-18 (2015).

38. Lei, D., Li, J., and Liu, Zh. "Supply chain contracts under demand and cost disruptions with asymmetric information", Int. J. Prod. Econ., 139, pp. 116-126 (2012).

39. Xiao, T. and Qi, X. "Price competition, cost and demand disruptions and coordination of a supply chain with one manufacturer and two competing retailers", Omega, 36, pp. 741-753 (2008).

40. Huang, S., Yang, C., and Zhang, X. "Pricing and production decisions in a dual-channel supply chain with demand disruption", Comput. Ind. Eng., 62, pp. 70-83 (2012).

41. Huang, S., Yang, C., and Liu, H. "Pricing and production decisions in a dual-channel supply chain when production costs are disrupted, Econ. Model, 30, pp. 521-538 (2013).

42. Xu, G., Dan, B., Zhang, X., et al. "Coordination a dual-channel supply chain with risk-averse under a two-way revenue sharing contract", Int. J. Prod. Econ., 147, pp. 171-179 (2014).

43. Zhang, J., Gou, Q., Liang, L., et al. "Supply chain coordination through cooperative advertising with reference price effect", Omega, 41, pp. 345-353 (2013).

44. Kopalle, P.K., Rao, A.G., and Assuncao, J.L. "Asymmetric reference price effects and dynamic pricing policies", Informs, 15, pp. 60-85 (1996). 
45. Lattin, J.M. and Buckin, R.E. "Reference effects of price and promotion on brand choice behavior", $J$. Marketing. Res., 26, pp. 299-310 (1989).

46. Geng, Q., Wu, C., and Li, K. "Pricing and promotion frequency in the presence of reference price effects in supply chain", California Journal of Operations Management, 8, pp. 74-82 (2010).

47. Zhang, J., Chiang, W.Y.K., and Liang, L. "Strategic pricing with reference effects in a competitive supply chain", Omega, 44, pp. 126-135 (2014).

48. Lin, Zh. "Price competition with reference price effects in supply chain", Transp. Res. E., 85, pp. 52-68 (2016).

49. Taleizadeh, A.A., Moshtagh, M.S., and Moon, L. "Optimal decisions of price, quality, effort level and return policy in a three level closed-loop supply chain based on different game theory approaches", Eur. J. Ind. Eng., 11(4), pp. 486-525 ( 2017).

50. Hsieh, C.C., Chang, Y.L., and Wu, C.H. "Competitive pricing and ordering decisions in a multiple-channel supply chain", Int. J. Prod. Econ., 154, pp. 156-165 (2014).

51. Zhang, R., Liu, B., and Wang, W. "Pricing decisions in a dual channels system with different power structures", Econ. Model, 29, pp. 523-533 (2012).

52. Mahmoodi, A. and Eshghi, K. "Price competition in duopoly supply chains with stochastic demand", $J$. Manuf. Syst., 33, pp. 604-612 (2014).

53. Li, J., Wang, S., and Cheng, TCE. "Competition and cooperation in a single-retailer two-supplier supply chain with supply disruption", Int. J. Prod. Econ., 124, pp. 137-150 (2010).

54. Husseinzadeh Kashan, A. "League championship algorithm: A new algorithm for numerical function optimization", Soft Computing and Pattern Recognition, pp. $43-48$ (2009).

55. Husseinzade Kashan, A. "League Championship Algorithm (LCA): A new algorithm for global optimization inspired by sport championships", Applied Soft Computing, 16, pp. 171-200 (2014).

\section{Appendix A}

The proofs of Eqs. (11) and (12) are as follows:

$$
\begin{gathered}
p_{i r t} d_{i r t}=p_{i r t} d_{i r t}\left(\int_{-\infty}^{z_{i r t}} f(x) d x+\int_{z_{i r t}}^{+\infty} f(x) d x\right), \\
\int_{-\infty}^{z_{i r t}} p_{i r t} x f(x) d x+\int_{z_{i r t}}^{+\infty} p_{i r t} z_{i r t} f(x) d x \\
=-\int_{-\infty}^{z_{i r t}} p_{i r t}\left(z_{i r t}-x\right) f(x) d x+p_{i r t} z_{i r t},
\end{gathered}
$$

$$
\begin{aligned}
p_{i r t} z_{i r t}= & p_{i r t} z_{i r t}\left\{\int_{-\infty}^{z_{i r t}} f(x) d x+\int_{z_{i r t}}^{+\infty} f(x) d x\right\} \\
& -p_{i r t}\left\{\int_{-\infty}^{z_{i r t}}\left(z_{i r t}-x\right) f(x) d x\right. \\
& \left.-\int_{z_{i r t}}^{+\infty}\left(x-z_{i r t}\right) f(x) d x+E\left(\varepsilon_{i r t}\right)\right\} \\
= & p_{i r t}\left\{\int_{-\infty}^{+\infty} z_{i r t} f(x) d x-\int_{-\infty}^{+\infty} x f(x) d x+E\left(\varepsilon_{i r t}\right)\right\} \\
= & p_{i r t}\left\{\int_{-\infty}^{z_{i r t}}\left(z_{i r t}-x\right) f(x) d x-\int_{z_{i r t}}^{+\infty}\left(x-z_{i r t}\right)\right. \\
& \left.f(x) d x+E\left(\varepsilon_{i r t}\right)\right\} .
\end{aligned}
$$

Upon replacing Eq. (A.3) with (A.2 ), Eq. (A.4) is obtained as follows:

$$
\begin{aligned}
& \int_{-\infty}^{z_{i r t}} p_{i r t} x f(x) d x+\int_{z_{i r t}}^{+\infty} p_{i r t} z_{i r t} f(x) d x \\
& \quad=-p_{i r t} \int_{z_{i r t}}^{+\infty}\left(x-z_{i r t}\right) f(x) d x+p_{i r t} E\left(\varepsilon_{i r t}\right) .
\end{aligned}
$$

$w_{i t}$ is obtained in the same way. Finally, the retailer's profit function is written as follows:

$$
\begin{aligned}
E\left(\Pi_{r t}\right)= & \sum_{i=1}^{2}\left\{\left(p_{i r t}-w_{i t}\right) d_{i r t}-\left\{\left(w_{i t}+h_{r}\right) \Phi\left(z_{i r t}\right)\right.\right. \\
& \left.+\left(p_{i r t}+b_{r}-w_{i t}\right) \Theta\left(z_{i r t}\right)\right\}+\left(p_{i r t}+w_{i t}\right) \\
& E\left(\varepsilon_{i r t}\right)+I_{r t-1}^{+} w_{i t} .
\end{aligned}
$$

\section{Appendix B}

The Hessian Matrix of $\pi_{r t}$ with respect to $p_{i r t}$ and $p_{(3-i) r t}$ is:

$$
\begin{gathered}
H=\left[\begin{array}{cc}
\frac{\partial^{2}(L)}{\partial p_{i r t}^{2}} & \frac{\partial^{2}(L)}{\partial p_{(3-i) r t} \partial p_{i r t}} \\
\frac{\partial^{2}(L)}{\partial p_{i r t} \partial p_{(3-i) r t}} & \frac{\partial^{2}(L)}{\partial p_{(3-i) r t}^{2}}
\end{array}\right], \\
\frac{\partial^{2} \Pi_{r t}}{\partial p_{i r t}^{2}}=\frac{\partial d_{i r t}}{\partial p_{i r t}}=-\left(\beta_{i j t}+g_{y, y=1,2}\right)<0,
\end{gathered}
$$




$$
\begin{aligned}
& \frac{\partial^{2}\left(\Pi_{r t}\right)}{\partial p_{(3-i) r t} \partial p_{i r t}}=\frac{\partial d_{(3-i) r t}}{\partial p_{i r t}}=y_{i r t}>0, \\
& \frac{\partial^{2}\left(\Pi_{r t}\right)}{\partial p_{i r t} \partial p_{(3-i) r t}}=\frac{\partial d_{i r t}}{\partial p_{(3-i) r t}}>0, \\
& \frac{\partial^{2}\left(\Pi_{r t}\right)}{\partial p_{(3-i) r t}^{2}}=\frac{\partial d_{(3-i) r t}}{\partial p_{(3-i) r t}}<0 .
\end{aligned}
$$

According to Eq. (A.2), the sign of the first subdeterminant of the Hessian Matrix is negative. To determine the sign of the determinant of the Hessian Matrix, some algebraic equations should be written as follows:

$$
\begin{gathered}
\frac{\partial^{2}\left(\Pi_{r t}\right)}{\partial p_{i r t}^{2}} \frac{\partial^{2}\left(\Pi_{r t}\right)}{\partial p_{(3-i) r t}^{2}}-\frac{\partial^{2}\left(\Pi_{r t}\right)}{\partial p_{(3-i) r t} \partial p_{i r t}} \frac{\partial^{2}\left(\Pi_{r t}\right)}{\partial p_{i r t} \partial p_{(3-i) r t}} \\
=\frac{\partial d_{i r t}}{\partial p_{i r t}} \times \frac{\partial d_{(3-i) r t}}{\partial p_{(3-i) r t}}-\frac{\partial d_{(3-i) r t}}{\partial p_{i r t}} \times \frac{\partial d_{i r t}}{\partial p_{(3-i) r t}}>0
\end{gathered}
$$

The sign of the determinant of the Hessian Matrix is positive under Eq. (7). The negative sign of the first subdeterminant and positive sign of the main determinant prove the strict concavity of $\Pi_{r t}$ with respect to $p_{\text {irt }}$ and $p_{(3-i) r t}$.

\section{Biographies}

Farnia Zarouri is a $\mathrm{PhD}$ candidate in Industrial Engineering at Kharazmi University, Iran. She received her MSc in Industrial Engineering from Tarbiat Modares University, Iran in 2015 and a BSc in Industrial Engineering from Urmia University of Technology (UUT ), Iran in 2013. She was ranked as the top Student in her BSc Course. Her main research interests are pricing, disruption management, coordination, and contracts in supply chain, inventory management (especially VMI inventory system), and revenue management.
Seyed Hesameddin Zegordi is a Professor of Industrial Engineering in the Faculty of Industrial \& Systems Engineering at Tarbiat Modares University, Iran. He received his $\mathrm{PhD}$ from the Department of Industrial Engineering and Management at Tokyo Institute of Technology, Japan in 1994. He holds an MSc in Industrial Engineering and Systems from Sharif University of Technology, Iran and a BSc in Industrial Engineering from Isfahan University of Technology, Iran. His main areas of teaching and research interests include production planning and scheduling, multiobjective optimization problems, meta-heuristics, quality management, and productivity. He has published several articles in international conferences and academic journals including European Journal of Operational Research, International Journal of Production Research, Journal of Operational Research Society of Japan etc.

Ali Husseinzadeh Kashan holds degrees in Industrial Engineering from Amirkabir University of Technology, Iran. He worked as a postdoctoral research fellow at the Department of Industrial Engineering and Management Systems. Dr. Kashan is currently an Assistant Professor at the Department of Industrial and Systems Engineering, Tarbiat Modares University. His research focuses on modeling and solving hard combinatorial optimization problems in areas such as logistics and supply networks, revenue management and pricing, resource scheduling, grouping problems, financial engineering, etc. He has introduced several intelligent optimization procedures inspired by natural phenomena such as League Championship Algorithm and Optics Inspired Optimization Grouping Evolution Strategies. Dr. Kashan has published over 70 peerreviewed journal and conference papers and served as a referee for several outstanding journals such as IEEE Transactions on Evolutionary Computations, Omega, Computers \& Operations Research etc. 